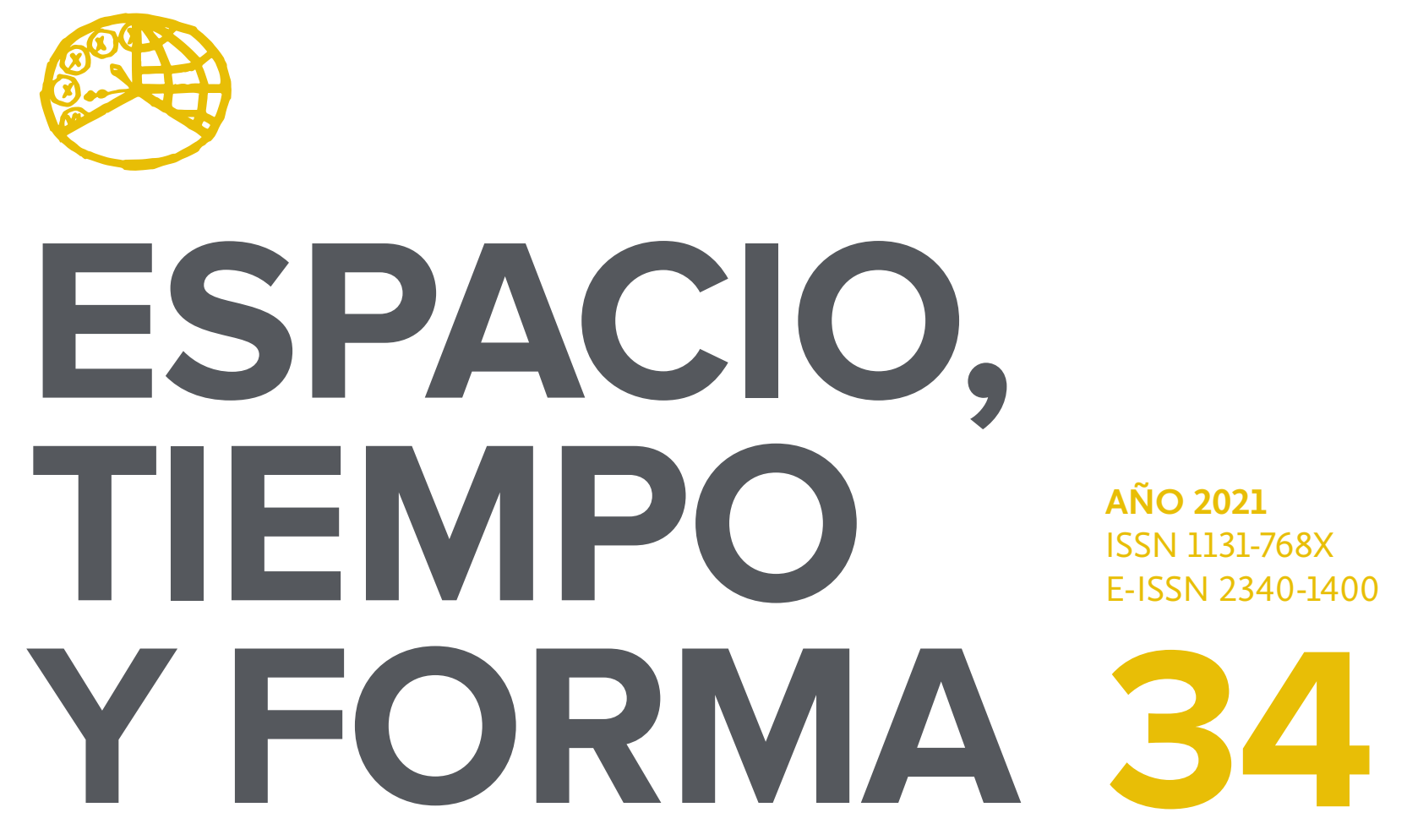

SERIE IV HISTORIA MODERNA

REVISTA DE LA FACULTAD DE GEOGRAFÍA E HISTORIA

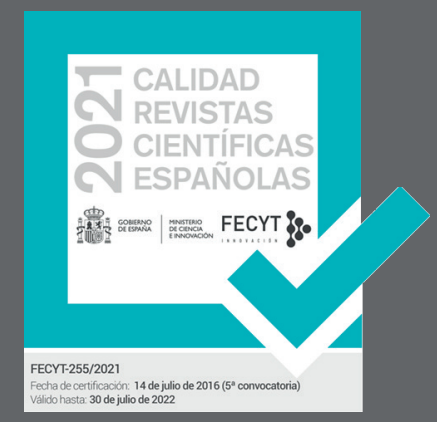




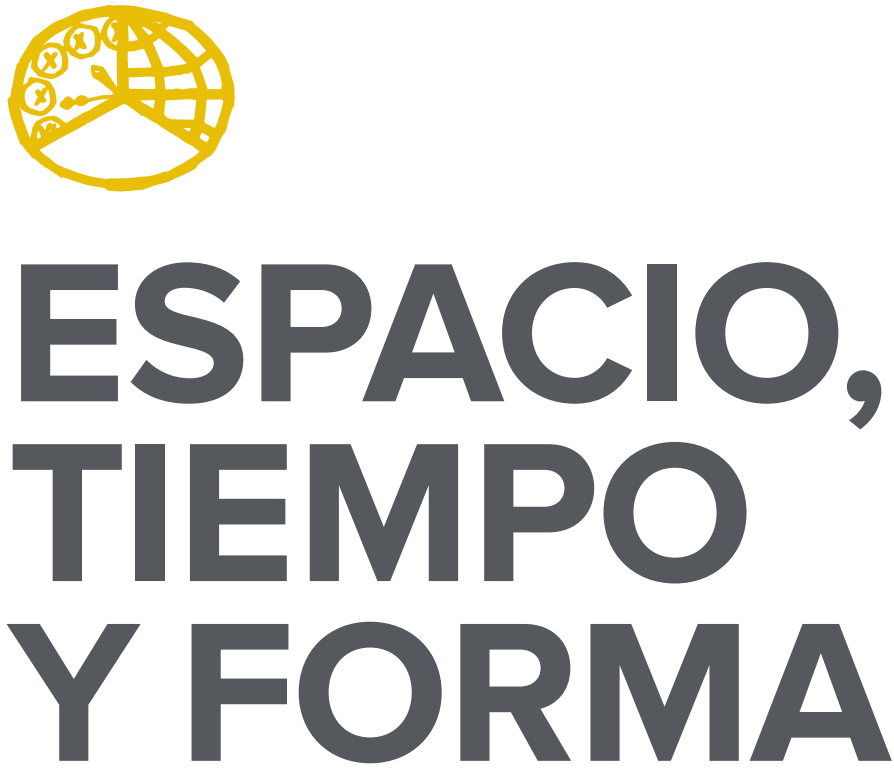

AÑO 2021

ISSN 1131-768X

E-ISSN 2340-1400

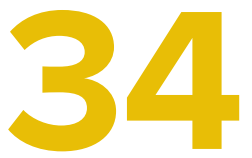

SERIE IV HISTORIA MODERNA

REVISTA DE LA FACULTAD DE GEOGRAFÍA E HISTORIA

DOI: https://doi.org/10.5944/etfiv.34.2021

\section{UกED}

UNIVERSIDAD NACIONAL DE EDUCACIÓN A DISTANCIA 
La revista Espacio, Tiempo y Forma (siglas recomendadas: ETF), de la Facultad de Geografía e Historia de la UNED, que inició su publicación el año 1988, está organizada de la siguiente forma:

$$
\begin{aligned}
& \text { SERIE I - Prehistoria y Arqueología } \\
& \text { SERIE II - Historia Antigua } \\
& \text { SERIE III - Historia Medieval } \\
& \text { SERIE IV - Historia Moderna } \\
& \text { SERIE V - Historia Contemporánea } \\
& \text { SERIE VI - Geografía } \\
& \text { SERIE VII - Historia del Arte }
\end{aligned}
$$

Excepcionalmente, algunos volúmenes del año 1988 atienden a la siguiente numeración:

$$
\begin{aligned}
& \mathrm{N} .^{\circ} 1 \text { - Historia Contemporánea } \\
& \mathrm{N}^{\circ} 2 \text { - Historia del Arte } \\
& \mathrm{N} .^{\circ} 3 \text { - Geografía } \\
& \mathrm{N} .^{\circ} 4 \text { - Historia Moderna }
\end{aligned}
$$

ETF no se solidariza necesariamente con las opiniones expresadas por los autores.

\author{
UNIVERSIDAD NACIONAL DE EDUCACIÓN A DISTANCIA \\ Madrid, 2021 \\ SERIE IV · HISTORIA MODERNA N. ${ }^{\circ} 34,2021$ \\ ISSN $1131-768 X \cdot$ E-ISSN 2340-1400 \\ DEPÓSITO LEGAL \\ M-21.037-1988 \\ URL \\ ETF IV · HISTORIA MODERNA · http://revistas.uned.es/index.php/ETFIV \\ DISEÑO Y COMPOSICIÓN \\ Carmen Chincoa Gallardo · http://www.laurisilva.net/cch \\ Impreso en España · Printed in Spain
}

(c) (7) (8) Esta obra está bajo una licencia Creative Commons Reconocimiento-NoComercial 4.0 Internacional. 


\section{MISCELÁNEA • MISCELLANY}





\title{
POLÍTICA COMERCIAL Y CIRCULACIÓN MONETARIA EN ARAGÓN: CONFLICTOS Y ACUERDOS CON CATALUÑA (1535-1565)
}

\section{TRADE POLICY AND MONETARY CIRCULATION IN ARAGON: CONFLICTS AND AGREEMENTS WITH CATALONIA (1535-1565)}

\author{
José Antonio Mateos Royo ${ }^{1}$ \\ Recibido: 06/04/2021 - Aceptado: 14/06/2021 \\ DOI: https://doi.org/10.5944/etfiv.34.2021.27299
}

\section{Resumen}

Este trabajo estudia la concesión y gestión de dos reformas arancelarias sobre la exportación de moneda de oro y plata efectuada por dos relevantes instituciones forales (Cortes y Diputación) del reino de Aragón durante el segundo tercio del siglo XVI. La primera reforma fue adoptada en 1547 para suprimir un conflicto aduanero promovido por la Diputación de Cataluña desde I535. La segunda reforma fue aprobada en 1564 , buscando favorecer el comercio, la movilidad del capital y la colaboración aduanera entre Aragón y Cataluña. Tras exponer los rasgos de la circulación monetaria en Aragón durante el siglo XVI, el artículo explora las etapas de negociación de estas reformas, considerando los intereses de instituciones y grupos sociales afectados. Por último, este estudio estima las consecuencias de estas reformas arancelarias sobre la circulación monetaria de Cataluña y Aragón durante el último tercio de esta centuria.

\section{Palabras clave}

Instituciones forales; reforma arancelaria; Aragón; Cataluña, siglo XVI

\section{Abstract}

This work studies the granting and management of two tariff reforms regarding the export of gold and silver coins carried out by two relevant regional institutions -the Cortes or Parliament and the Diputación- of the kingdom of Aragon during the second third of the $16^{\text {th }}$ century. The first reform was adopted in 1547 in order

\footnotetext{
1. Universidad de Zaragoza; jmateos@unizar.es

Este artículo se enmarca dentro del proyecto de investigación PGC2018-097683-B-100, financiado por el Ministerio de Ciencia, Innovación y Universidades. El autor desea agradecer las sugerencias recibidas por parte de dos evaluadores anónimos de la revista Espacio, Tiempo y Forma.

Archivo de la Corona de Aragón [ACA], Consejo de Aragón [CA], Secretaría de Aragón [SA]. Archivo de la Diputación Provincial de Zaragoza [ADPZ], Actas de la Diputación del Reino [ADR].
} 
to suppress a customs conflict which was prompted by the Diputación of Catalonia since 1535 . The second reform was approved in 1564 , seeking to promote trade, capital mobility and customs cooperation between Aragon and Catalonia. After the presentation of the main features of monetary circulation taking place in Aragon during the $\mathrm{I}^{\mathrm{th}}$ century, this article explores the negotiation stages for these reforms, paying attention to the interests of affected institutions and social groups. Finally, this paper estimates the impacts of these tariff reforms on monetary circulation of Catalonia and Aragon during the last third of this century.

Keywords

Regional institutions; tariff reform; Aragon, Catalonia; $\mathrm{I}^{\text {th }}$ century 


\section{INTRODUCCIÓN}

El estado actual de las investigaciones sobre la política y circulación monetaria en la España Moderna refleja un fuerte desequilibrio. Beneficiados por su imbricación con las finanzas y política exterior de la monarquía hispánica, así como su fuerte incidencia en la economía española, europea y mundial, los estudios sobre la moneda castellana que -con notables precedentes- cobraron vigor desde mediados del siglo XX y sobre todo en las décadas de 1960 y $1970^{2}$, han renacido con fuerza entre los años 1990 y 20Io. Con especial énfasis en el siglo XVII, economistas e historiadores han mostrado gran interés por analizar las causas y consecuencias de la política monetaria practicada en Castilla como núcleo del Imperio español, exponiendo sus nexos con sus políticas comerciales y fiscales 3 . Por el contrario, el mayor abandono de estos estudios para la Corona de Aragón no sólo ha impedido adoptar líneas de trabajo similares o abordar nuevas hipótesis, sino generar una visión más completa y contrastada de la circulación monetaria en los territorios hispánicos durante el Antiguo Régimen.

Frente a la atención prestada a la política y circulación monetaria en la Corona de Aragón durante la Edad Media, por estimarse pactada entre monarquía e instituciones forales y constituir un rasgo de identidad territorial, los historiadores han marginado su estudio para la Edad Moderna. El análisis de la política monetaria en este período perdía interés por considerarse supeditada a las directrices del Estado español gestado en Castilla por la monarquía de los Austrias hasta disponer la nueva dinastía borbónica la extinción de las piezas autóctonas emitidas en dicha Corona en el siglo XVIII. Muchas aportaciones sobre circulación monetaria en la Corona de Aragón durante la Edad Moderna han procedido así de estudios numismáticos -a menudo, como colofón de los dedicados a la moneda medieval-, con objetivos distintos a los de la investigación histórica ${ }^{4}$. Por estos motivos, pese a existir trabajos pioneros sobre los vínculos entre la emisión de moneda y la evolución de los precios en Valencia y Cataluña ${ }^{5}$, las causas económicas que afectaron a la acuñación y oferta de numerario en la Corona de Aragón durante la Edad Moderna no han sido tratadas lo suficiente. Respecto a los factores institucionales, con especial énfasis para los siglos XVI y XVII, las conexiones entre las políticas monetarias, fiscales y comerciales aplicadas en cada reino requieren un mayor estudio, explorando consensos y conflictos entre instituciones forales y reales. Dado que se trata de un aspecto poco atendido por una investigación de marcado carácter identitario centrada en el análisis exclusivo de un territorio, se

2. Junto al estudio pionero de HEISS, 1865-69, destacan como trabajos numismáticos MATEU Y LLOPIS, 1946. FONTECHA Y SÁNCHEZ, 1968. GIL FARRÉS, 1976. Entre los análisis económicos, HAMILTON, 1975 y 1980. VICENS VIVES 1959. DOMÍNGUEZ ORTIZ, 1960; 1973.

3. Sánchez Belén, 1992. Motomura, 1994. Serrano Mangas, 1996. Álvarez Nogal, 1997; 2001. Andrés Ucendo, 1999. García de Paso, 2000. Santiago Fernández, 2000. Bernal Rodríguez (ed.), 2000. García GueRRA, 1999. 2003. 2006. FONT DE VILLANUEVA, 2005 Y 2008.

4. Como obras de síntesis representativas, Mateu y Llopis, 1929 y 1983. Beltrán Villagrasa, 1977. Gil FarRÉs, 1976. Crusafont y Sabater, 1989; 1996. Sanahuja Anguera, 2013.

5. HAMILTON, 1975; 1980. VILAR, 1978, vol. I: 390-405. 
precisa una adecuada comparación de las políticas adoptadas en todos ellos para comprender mejor sus repercusiones sobre la circulación monetaria de la Corona de Aragón en su conjunto.

Bajo estas consideraciones previas, este artículo estudia los nexos entre política comercial y circulación monetaria en el Aragón del siglo XVI a través de la gestión de un conflicto aduanero con Cataluña que afectó a los aranceles sobre la exportación de piezas de oro y plata en el segundo tercio de dicha centuria. Las reformas sobre esta materia fueron aprobadas y gestionadas por dos relevantes instituciones forales: las Cortes o cámara legislativa y la Diputación, constituida ya durante el siglo XV en su delegación permanente encargada del gobierno, defensa y preservación de las leyes del reino ${ }^{6}$. Un primer apartado explica la política monetaria gestada en Aragón durante el siglo XVI, que aceptó depender de las piezas castellanas de oro y plata para practicar el comercio ante el declive de las emisiones autóctonas. Un segundo apartado detalla las causas del conflicto aduanero iniciado por Cataluña en 1535 , ligadas a la apreciación del oro frente a la plata, litigio que afectó a los flujos monetarios entre reino y principado durante doce años. El tercero expone las reformas arancelarias sobre la salida de piezas de oro y plata aprobadas por las Cortes de Aragón y Cataluña en I547 para extinguir dicho conflicto y en 1563-I564 para fomentar la movilidad del capital, la cooperación aduanera y el comercio mutuos. Un cuarto apartado explora los cambios detectados en los flujos monetarios, las actividades financieras y las transacciones exteriores de ambos territorios durante el último tercio del siglo $\mathrm{XVI}$ para valorar la posible incidencia de la reforma de 1564 . El quinto apartado recoge las principales conclusiones de estudio.

\section{POLÍTICA Y CIRCULACIÓN MONETARIA EN ARAGÓN DURANTE EL SIGLO XVI}

La política monetaria llevada a cabo por las instituciones reales y forales en Aragón durante el siglo XVI deriva de las reformas realizadas en este campo bajo los reinados de Juan Il y Fernando el Católico (I458-1516). Estas se hallaban orientadas a lograr una mejor adaptación del valor intrínseco de las piezas aragonesas tanto a la cotización del oro y la plata en el mercado como al contenido metálico de las piezas acuñadas en otros reinos hispánicos y europeos. Buscaban así solventar dificultades endémicas del sistema monetario aragonés durante la Baja Edad Media, vinculadas a la escasez y el elevado valor intrínseco de la moneda autóctona, inadecuada para satisfacer la demanda del mercado por estos motivos ${ }^{7}$. A diferencia de Cataluña y Valencia, Aragón no emitió moneda de plata hasta fines del siglo XV. La acuñación de florines de oro se limitó a un breve período (I349-I37I)

6. Sobre el carácter y gestión de estas instituciones aragonesas en el siglo XVI, BLANCO LALINDE, 1996. JARQUE Martínez \& Salas Ausens, 2001-2002.

7. Zulaica Palacios, 2003, vol. I: 607-32. 
al ser abandonada por el rey Pedro IV ante la resistencia de las elites regnícolas a reducir su valor intrínseco. Los aragoneses utilizaron piezas de oro y plata extranjeras, emitidas a menudo en otros territorios de la Corona, para sus intercambios. Práctica ya vigente a mediados del siglo XV, la Diputación sólo gravó con un 2,5\% la salida de moneda de oro, quedando exentas tanto la importación de piezas de oro y plata como la exportación de aquellas de plata para favorecer la circulación monetaria ${ }^{8}$. Más serios problemas causó al comercio en Aragón la insuficiente emisión de moneda jaquesa de vellón y su alto valor intrínseco, que favorecía su exportación y generaba una endémica escasez de moneda fraccionaria durante los siglos XIV y XV. La preservación de un notable contenido en plata por dicha moneda de vellón se ha vinculado al éxito de los grupos nobiliarios en impedir que el rey rebajase su peso y ley con el fin de mantener su valor nominal, aquel que determinaba los verdaderos ingresos obtenidos de las rentas generadas por sus tierras y censales al constituir el dinero la unidad de referencia del sistema oficial de cuenta para toda la Corona de Aragón'. Ante estos inconvenientes, la propia demanda del mercado favoreció la falsificación y adulteración del vellón autóctono, pese a su prohibición por parte de las Cortes aragonesas.

Con el fin de erradicar estos problemas, las reformas aprobadas por las Cortes aragonesas bajo Juan Il y Fernando el Católico cambiaron de raíz la tipología monetaria de Aragón ${ }^{10}$. Juan Il acuñó en Valencia y Zaragoza en I477 escudos y medios escudos de oro, denominados juanines y medio juanines. Este escudo juanín se convirtió en el precedente del ducado aragonés. Moneda de origen veneciano con gran prestigio por su alto contenido de oro, el ducado se fabricó en toda la Corona de Aragón bajo Fernando II, pese a la acuñación esporádica del florín, abandonado por su menor contenido metálico tras haber sido moneda común de dicha Corona durante la Baja Edad Media. El auge del ducado se consolidó con su adopción por Castilla en sustitución de la dobla almohade, propiciada por el rey Fernando en 1497 con el fin de crear una única moneda áurea para las Coronas de Aragón y Castilla: denominado excelente de granada, poseía una ley de 23 3/4

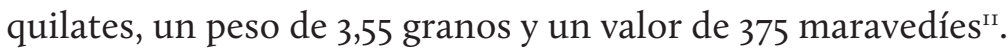

Idéntica homogeneización con Castilla perseguía la emisión de reales y medios reales en la ceca de Zaragoza bajo Juan II en I475-I477 y Fernando II en I484 y I503-I506, sujeta a vacilaciones sobre su peso ${ }^{12}$. Ambos con una ley de II dineros, el real emitido en I475-I477 pesaba 3,20 gramos mientras el medio real acuñado en I484 alcanzaba los I,80 gramos. Al aceptar las Cortes de I484 que este medio real equivaliese a un sueldo, la emisión de piezas de plata en Aragón forzó a rebajar la ley del dinero jaqués a la mitad -de tres dineros hasta un dinero I2 granos- para mantenerlo como unidad de referencia del sistema oficial de cuenta, junto con sus

8. Sesma MUÑOZ, 2013: 116-17.

9. Crusafont y Sabater, 1996: 96-7.

10. Beltrán Villagrasa, 1972, t. II: 448-56. Gil Farrés, 1976: 276-77. Mateu y Llopis, 1983: 113-15. Zulaica PALACIOS, 2006: 304-07.

11. Santiago Fernández, 2000: 28-32.

12. Véase la nota 10 y SESMA MUÑOZ, 1986: 1034-36. 
múltiplos tradicionales: el sueldo, equivalente a doce dineros y la libra, a veinte sueldos $^{13}$. Dicha depreciación buscaba retener la moneda autóctona de vellón en Aragón; pero la oposición de las elites logró reducir las emisiones de dineros aprobadas ese año. Presionadas por la falta de moneda fraccionaria, las Cortes de 1503 ordenaron acuñar todos los valores del nuevo sistema monetario aragonés: ducados y medios ducados de oro, reales y medios reales de plata y dineros y medios dineros o miajas de vellón. Esta emisión sólo culminó en I506, al demorarse la fabricación de vellón, en especial por los intereses de los cambistas ${ }^{14}$.

Ya bajo el reinado de Carlos V, esta escasez de piezas fraccionarias llevó en 1519 a las Cortes aragonesas a ordenar la fabricación, junto a reales y medio reales que adoptasen el peso y la ley de Castilla, de 20.000 libras de vellón cuyo valor intrínseco se acomodó al de las nuevas piezas de plata para mantener el sistema oficial de cuenta. En I528 las Cortes aprobaron la emisión de ducados y medios ducados con el peso y la ley de Castilla, así como reales, medios reales, dineros y miajas bajo las condiciones establecidas en $1519^{15}$. Estas disposiciones no sólo ampliaron la oferta de moneda aragonesa, sino culminaron las reformas anteriores al estipular la aplicación del valor intrínseco utilizado en Castilla a las nuevas piezas de oro y plata, constituido así en referente de las escasas acuñaciones de estas monedas en Aragón durante los siglos XVI y XVII. Esta homogeneización no fue absoluta: si el real aragonés tenía un peso similar al castellano (3,42 frente a 3,43 gramos), preservó una ley inferior (II dineros frente a II dineros y 4 granos) ya aplicada en I476-I477, I484 y I503-I506 ${ }^{16}$. Con todo, ambas normas facilitaron el uso mercantil de las monedas de oro y plata acuñadas en Castilla al hacer equivaler sus valores nominales al de las piezas autóctonas y favorecer sus conversiones con la moneda jaquesa, vellón preponderante en Aragón durante el siglo XVI.

La apuesta por utilizar piezas castellanas respondía a la dificultad de emitir suficientes monedas de oro y plata en Aragón por varios motivos. Como reconoció la Diputación en 1548 , el reino padecía una carencia de oro y plata «en pasta» -en barras o lingotes- que con frecuencia impedía fabricar piezas compuestas de estos metales en la ceca de Zaragoza ${ }^{\text {17. }}$. Con el fin de facilitar las acuñaciones de reales, las Cortes de I5I9 proclamaron un acto de corte que permitía la entrada de plata «en pasta» libre de arancel en Aragón; pero no así la de plata labrada ${ }^{18}$. Desde mayo de I536, la Diputación estipuló la exención del oro y plata introducidos como metal o «en masa» en el reino en todos los contratos de arriendo de derechos aduaneros

13. Extraño a Castilla, este sistema de cuenta fue el más difundido en Europa Occidental durante las Edades Media y Moderna. Resultaba vigente en toda la Corona de Aragón, Estados del Norte y centro de Italia, Francia y los Países Bajos, según García Guerra, 2000: 20-21.

14. Sobre las dificultades de las emisiones de vellón aprobadas por las Cortes de 1484 y 1503, BELTRÁN VILLAGRASA, 1972, t. II: 454. ZulaicA PALACIOS, 2006: 305, notas 26 y 29; 307. Las elites aragonesas solían fijar el valor de las rentas obtenidas de sus tierras y censales durante la Baja Edad Media en moneda jaquesa con una ley de tres dineros. Por tanto, cualquier rebaja de su valor intrínseco disminuía estos ingresos. Véase CRUSAFONT Y SABATER, 1996: 96-97.

15. Savall y Dronda \& Penén Debesa, 1866, vol. I: $335-36$ y vol. II: 342.

16. GIL FARRÉS, 1976: 276-78, 439-42. LASTANOSA, 1681: 63.

17. MATEu y Llopis, 1943: 590.

18. Savall y Dronda \& Penén Debesa, 1866, vol. II: 342 
firmados en el siglo XVI ${ }^{19}$. Dado que los reyes de Aragón renunciaron ante las Cortes durante la Edad Media a todo señoreaje a cambio de recibir el impuesto del maravedí o monedaje ${ }^{20}$, Carlos $\mathrm{V}$ y Felipe Il carecían de alicientes fiscales para conceder a las Cortes nuevas emisiones y facilitar a la ceca de Zaragoza los metales preciosos necesarios. Tras aprobar las acuñaciones de I5I9 y I528, durante el resto de la centuria, dichas Cortes sólo autorizaron así en 1564 la fabricación de escudos de oro -de nuevo, con la ley y el peso de Castilla- y miajas de vellón, sin quedar constancia documental o numismática de que se llevase a efecto ${ }^{21}$.

Las normas de fabricación de moneda impuestas por ley y costumbre en Aragón para garantizar su valor intrínseco limitaban la obtención de beneficios al monarca y al maestro de la ceca de Zaragoza, dueño de la concesión real para fabricar moneda, hasta el punto de mermar su actividad emisora durante el siglo $\mathrm{XVI}^{22}$. Como recordaron las Cortes aragonesas a Fernando el Católico en I482, un fuero dictaba que las acuñaciones de moneda de oro y plata en Aragón junto con sus características debían ser aprobadas por esta asamblea ${ }^{23}$. Al decretar las emisiones de I519 y I528, dichas Cortes dispusieron que su cuantía, peso y ley fueran fijadas por una delegación formada por representantes del rey y del reino ${ }^{24}$. Dificultadas por estos controles, las fabricaciones de ducados cesaron y las de reales sólo se retomaron en la ceca de Zaragoza a mediados del siglo XVI; pero ya al margen de la supervisión de las Cortes ${ }^{25}$. Los derechos de fabricación obtenidos por el maestro de la ceca eran modestos: Miguel Martínez de Luna, conde de Morata y virrey de Aragón los cifró en 1593 en cinco reales por marco de oro, un real por marco de vellón y sólo dos dineros por marco de plata ${ }^{26}$. Abandonada toda emisión de escudos y reales en el último cuarto del siglo XVI, su principal fuente de ingresos procedió de fabricar dineros jaqueses, cuyo valor intrínseco podía ser rebajado de forma subrepticia al no haber sido fijado ni asimilado al del vellón castellano por las Cortes aragonesas ${ }^{27}$. Hernando de Tujarón, maestro de dicha ceca entre 159I y I593, llegó a remitir las

19. ADPZ, ADR, Ms. 141, f. 105V-106r.

20. Beltrán Villagrasa, 1972, t. II: 399-402. Orcastegui Gros, 1983. La concesión de este derecho al monarca se vinculó en Aragón durante la época foral a la obligación de preservar el valor intrínseco de la moneda jaquesa. Véase LASTANOSA, 1681: 9-10.

21. Savall y Dronda \& Penén Debesa, 1866, vol. I: 406-07.

22. Por este motivo, el Consejo de Aragón afirmó sin ambages en 1593 la menor utilidad de la ceca de Zaragoza para la monarquía hispánica, frente a las sitas en Valencia y Barcelona. Véase ACA, CA, SA, leg. 36, doc. 324.

23. MATEU y LLOPIS, 1983: 115.

24. Savall y Dronda \& Penén Debesa, 1866, vol. I: $335-36$ y vol. II: 342.

25. Estudios numismáticos han revelado la existencia de reales aragoneses de a cuatro fabricados en 1547 y 1554, de a ocho en 1556 y de a diez reales en 1554. También se conserva vellón jaqués batido en 1555 ó 1556 . En todos los casos, se desconoce la cuantía y finalidad de la acuñación: ensayos para futuras emisiones, uso conmemorativo, consecución de beneficios al maestro de la ceca o respuesta a la demanda del mercado. Véase GIL FARRÉS, 1976: 440. Mateu y Llopis, 1983: 118-19. Crusafont y SAbater, 1983: 222, 228. Sanahuja Anguera, 2003: 102.

26. ACA, CA, SA, leg. 36, docs. 323 y 324 y Tesorería, vol. 111, papel suelto entre folios 45 y 46 titulado memoria de los oficios y salarios de la Casa de la Moneda del reino de Aragón, sin fechar. El escaso margen de ganancia concedido al maestro de la ceca de Zaragoza imponía moderar el braceaje o gastos de fabricación de la moneda al máximo. Sobre estos, ACA, CA, SA, leg. 91, relación de gastos y emolumentos de la Casa de la Moneda, sin fechar.

27. ACA, CA, SA, leg. 91, informe de la Real Audiencia, 26 de octubre de 1660, informe de Jerónimo Villanueva, 21 de diciembre de 1674 y provisiones de tránsito de moneda de plata hechas en el reino de Aragón, sin fechar. Este documento cita un examen efectuado en 1609 de dineros acuñados en Aragón durante los 160 años anteriores que tenían una ley inferior en dos o tres granos a la acostumbrada. 
emisiones de dineros allí realizadas directamente a Valencia como estrategia para aumentar sus beneficios ante la escasa demanda del mercado aragonés ${ }^{28}$.

Condicionada por el permanente déficit de la balanza comercial de Castilla y los empréstitos de la monarquía hispánica ${ }^{29}$, que drenaban piezas de oro y plata hacia otros territorios europeos, la oferta de ambas monedas en Aragón difirió lo suficiente para gestar distintas políticas comerciales. Pese al declive de las emisiones autóctonas y la creciente exportación del real castellano o aragonés por su mayor intrínseco que

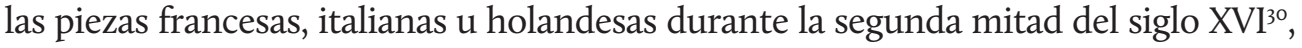
al disponer de un abasto suficiente, Aragón mantuvo la libre circulación de monedas de plata: la prohibición temporal de su extracción dictada por la Diputación en mayo de 1535 sólo se repitió en septiembre de I57I y ya limitada a los territorios no gobernados por la monarquía hispánica ${ }^{31}$. Por el contrario, ante la apreciación del oro frente a la plata en los mercados europeos ${ }^{32}$, la carencia de ducados y escudos era palpable en Aragón ya a mediados de siglo: si la Diputación vetó en mayo de 1545 su exportación a tierras no regidas por la monarquía hispánica entre 1546 y I548, las Cortes de I547 prohibieron la salida de oro en barras a Francia y el Béarn ${ }^{33}$. Tras considerar esta medida insuficiente, la Diputación prohibió exportar piezas de oro a ambos territorios durante las tres últimas décadas de la centuria ${ }^{34}$. Reforzó la vigilancia aduanera para contener la frecuente extracción subrepticia de piezas de oro hacia Cataluña y Francia ${ }^{35}$. $\mathrm{Al}$ demorarse la convocatoria de Cortes que pudieran aprobar emisiones, ordenó en I575 la fabricación de doblones -escudos dobles- en la ceca de Zaragoza. Detenida por el virrey Artal de Alagón, conde de Sástago, en agosto de 1576 al no haber acordado la Diputación las normas de emisión con ninguna autoridad real, su cuantía final se fijó en sólo 2.000 doblones pese a disponerse de oro para fabricar Io.000 monedas. El virrey y los diputados se repartieron mitad por mitad estos doblones y sus gastos de acuñación ${ }^{36}$.

Gracias a la rebaja del valor intrínseco acordada en las emisiones de I5I9 y I528, la oferta de vellón respondió mejor a la demanda del mercado durante el siglo XVI, desapareciendo las protestas sobre la falta de moneda fraccionaria tan comunes a fines

28. ACA, CA, SA, leg. 36, docs. 322 y 323. Estos datos avalan la emisión de vellón aragonés bajo Felipe II, discutida en CRUSAFONT Y SABATER, 1983: 221-32 y rechazada en SANAHUJA ANGUERA, 2003: 94-95.

29. Se ha estimado así que el déficit de la balanza comercial de Castilla alcanzó un 30\% del valor de las importaciones a fines del siglo XVI. Véase PÉrez GARCíA, 1988, vol. VI: 270. Sobre el endeudamiento de la monarquía hispánica de los Austrias en el siglo XVI, entre otros, véase CARANDE, 1949-67. CASTILlo PINTADO, 1963a; 1963b. RUIZ Martín, 1968. Ulloa, 1986. de Carlos Morales, 2008.

30. La moneda oficial de plata perdió así un $66 \%$ de su contenido argentífero en Francia entre 1514 y 1666, así como entre un 20\% y $30 \%$ en Génova, Milán y Venecia durante la segunda mitad del siglo XVI. Según los arbitristas españoles Cardona y Lasheras, las piezas de plata emitidas en Holanda rebajaron su valor intrínseco un $44 \%$ entre 1548 y 1622. Sobre el tema, GLASSMAN \& REDISH, 1988: 86-87. CIPOLLA, 1994: 61 y Biblioteca Nacional, VE-13-29 y Manuscrito 6384-129.

31. ADPZ, ADR, Ms. 141, f. 9v-10r; Ms. 217, f. 68v-69r

32. LóPEZ GONZÁLEZ, 1996: 15.

33. ADPZ, ADR, Ms. 154, f. 43 V y Savall y Dronda y Penén Debesa, 1866, vol. II: 352

34. Así se aprecia en los contratos de arriendo de derechos aduaneros firmados por la Diputación desde mayo de 1569. Véase ADPZ, ADR, Ms. 205, f. 206v-207v, Ms. 217, f. 254v-255r, Ms. 221, f. 183r-186r, Ms. 255, f. 339r-340v, Ms. 263, f. 50v-51v, Ms. 280, f. 451r-452v, Ms. 653, n6, f.19v-20v.

35. ADPZ, ADR, Ms. 221, f. 74r, 177v-181v, 183r, 185r-186r, Ms. 231, f. 8or-81r, Ms. 276, f. 133r-140r, Ms. 280 , f. $265 \mathrm{v}$.

36. ADPZ, ADR, Ms. 231, f. 68v-69v, 100r-104v, 120r-131r, 18gr-196r, 201r-v. 
del siglo XV y principios del siglo XVI ${ }^{37}$. Las vedas de exportar monedas jaquesas de vellón -dineros, miajas- acordadas por la Diputación entre 1528 y 1536 al arrendar los derechos aduaneros ${ }^{38}$, destinadas a retener en el reino las piezas emitidas en I528, no se repitieron. Para suplir las carencias de vellón autóctono, Aragón admitió durante el segundo tercio del siglo XVI el uso de las blancas fabricadas en Castilla, práctica que decrecería tras rebajarse su ley en las nuevas emisiones realizadas desde ${ }^{5666^{39}}$. En su último cuarto, la moderada demanda de vellón del mercado aragonés podía satisfacerse con acuñaciones modestas ${ }^{40}$. Estas emisiones resultaron factibles al ser gestionadas por la Diputación y el virrey sin requerir el control previo de las Cortes. Forzada a detener la fabricación de doblones, la Diputación ordenó en 1576 la emisión de 20.000 libras de vellón por la ceca de Zaragoza ${ }^{41}$. Al detectarse la carencia de dineros en el reino por su exportación a Valencia, tras consultar con el Consejo de Aragón, Beltrán de la Cueva y Castilla, duque de Albuquerque y virrey de Aragón ordenó en I597 emitir I2.00o libras de vellón en esta ceca, pese a generar casi nulos beneficios a la hacienda real ${ }^{42}$.

La adecuada oferta de piezas de plata y vellón, ya fuesen autóctonas o castellanas, a la demanda del mercado aragonés se evidencia no sólo en su suficiente cantidad, sino en la carencia de problemas monetarios comunes durante la segunda mitad del siglo XV y principios del XVI, retomados durante los siglos XVII y XVIII ${ }^{43}$. Al margen de la utilización complementaria de las blancas castellanas, Aragón no sufrió durante el siglo XVI frecuentes invasiones de piezas de plata y vellón emitidas en territorios vecinos -Valencia, Cataluña, Béarn- que sustituyesen a las piezas aragonesas o castellanas utilizadas, siguiendo la ley de Gresham, gracias a su menor peso o ley ${ }^{44}$. A diferencia de Cataluña, donde la fabricación o importación de vellón falso y plata recortada proliferaron en la segunda mitad del siglo $\mathrm{XVI}^{45}$, las falsificaciones y cercenes de reales y dineros tampoco demandaron la atención de instituciones y cargos públicos (Cortes, Diputación, virrey, municipios) en Aragón por su intensidad hasta principios del siglo XVII. Ambos factores facilitaron la preservación de la moneda castellana y aragonesa de mayor valor intrínseco. La consiguiente mayor disponibilidad de numerario de plata y vellón contribuyó a la aceptación de la política monetaria por parte de las instituciones forales en el Aragón del siglo XVI, pese a las escasas emisiones de piezas autóctonas.

37. Zulaica Palacios, 2006: 300-07.

38. ADPZ, ADR, Ms. 124, f. $42 \mathrm{v}$, Ms. 129; f. $95 \mathrm{v}, \mathrm{Ms} .143$, f. $27 \mathrm{r}$

39. ADPZ, ADR, Ms. 146, f. 49r-v., Ms. 154, f. 44r-v., Ms. 193, f. 79 r-v. Esta moneda fue acuñada en Castilla desde 1497 con un peso de 1,197 gramos y ley de 7 granos, fineza reducida a 5 granos y medio por Carlos V en 1552. Felipe II rebajó en 1566 su peso a 1,045 gramos y su ley a sólo 4 granos. Véase SANTIAGO FERNÁNDEZ, 2000: 31, 37, 40.

40. Así lo indico el virrey de Aragón, Miguel Martínez de Luna, en 1593 al Consejo de Aragón. Véase ACA, CA, SA, leg. 36, doc. 323.

41. ADPZ, Ms 231, f. 194V-195r.

42. ACA, CA, SA, leg 92, Informes de Villanueva y del virrey de Aragón, 29 de mayo y 5 de septiembre de 1597. El virrey atribuyó dicha exportación a la apreciación del dinero aragonés en los mercados de Valencia por su mayor valor intrínseco que el vellón autóctono, que permitía obtener un premio de un dinero por real -un 2,5\% de su valorpor su utilización en las transacciones.

43. Mateos Royo, 1997: 208-10. 2006: 159-64. 2009: 183-95.

44. Incursiones esporádicas de moneda extranjera a nivel local, como las de los coronados navarros detectados en Daroca a mediados del siglo XVI, fueron detenidas por los municipios sin generar ulteriores problemas. Véase Archivo Municipal de Daroca, Actas municipales, 1549, 16 de abril.

45. VILAR, 1978, vol. I: 348-49. SAnAhUJA ANGUERA, 2013: 1069-71. 1077-81. 1083-84. 


\section{EL CONFLICTO ADUANERO ENTRE ARAGÓN Y CATALUÑA: CONTEXTO, PRECEDENTES, ESTALLIDO Y EVOLUCIÓN (1535-1547)}

El conflicto aduanero analizado resulta significativo por dos motivos. En primer lugar, supuso la última disputa comercial seria entre Aragón y Cataluña durante el siglo XVI: iniciado en I535, su superación en 1547 erradicó conflictos que habían dañado las transacciones mutuas durante más de seis décadas. En segundo término, su estallido propició la adopción de dos reformas arancelarias exclusivas entre reino y principado sobre la exportación de monedas de oro y plata: aprobada en 1564, la segunda reforma perduró el resto de la época foral moderna. Dominados progresivamente sus flujos monetarios por las piezas castellanas de oro y plata ${ }^{46}$, ambos territorios buscaron con estas reformas mejorar su oferta monetaria conforme el mercado demandó más liquidez y los ducados y escudos escasearon frente a los reales emitidos con plata americana ${ }^{47}$. Consecuencia añadida, este desequilibrio generó en Europa una apreciación creciente del oro frente a la plata que obligó a sus autoridades públicas a modificar la relación bimetálica a favor del oro en el segundo tercio del siglo $\mathrm{XVI}^{4}$. Dos medidas monetarias adoptadas en Castilla al inicio y final de dicho período responden a este reajuste. La primera es la sustitución del ducado por el escudo, de menor valor intrínseco al tener un peso de 3,38 gramos y ley de 22 quilates, aprobado por las Cortes castellanas en 1537 tras fabricarse en la ceca de Barcelona en mayo de 1535 y ensayarse su aceptación en la campaña militar de Túnez ${ }^{49}$. La segunda es el aumento del valor nominal del escudo desde 350 hasta 400 maravedíes ordenado por Felipe Il en I566, acrecentando su cotización frente a un real de plata cuyo valor siguió fijado en 34 maravedíes $^{50}$.

Los enfrentamientos comerciales que precedieron al conflicto aquí tratado se iniciaron con la imposición de represalias en Cataluña a comerciantes aragoneses -que se traducían en la incautación de sus mercancías- a fines del siglo XV y en el primer tercio del siglo XVI, aprobadas por jueces locales tras considerar que ciertos catalanes no habían sido tratados con justicia en Aragón al reclamar allí sus deudas. Un primer ciclo de represalias se desató en I 484 por el impago a censalistas catalanes de pensiones caídas entre I462 y I472 por la Diputación de Aragón como castigo a su rebelión contra Juan Il y los retrasos en sus abonos durante el reinado de Fernando el Católico. Una concordia dictada en I499 por el arzobispo de Zaragoza Alonso de Aragón, representante del rey Fernando, en términos relativamente favorables a dicha institución puso fin a las represalias. Medida adicional, las Cortes aragonesas

46. Sobre el decrecimiento de las emisiones autóctonas en Aragón y Cataluña durante el siglo XVI, MATEOS Royo, 2006: 157-58. Crusafont y Sabater, 1989: 165-70. Sanahuja Anguera, 2013: 431-76.

47. VILAR, 1974: 138-42. RUIZ MARTÍN, 1990: 33-34.

48. LóPEZ GONZÁLEZ, 1996: 15.

49. Pérez Sindreu, 1992: 279-95. Esta fabricación de escudos en la ceca de Barcelona en 1535 prueba que, en el año en que estalló el conflicto aduanero con Aragón, la Generalitat de Cataluña sabía que la monarquía hispánica consideraba adoptar el escudo como moneda oficial de Castilla, cuyo menor valor intrínseco favorecería la exportación de los ducados emitidos en Cataluña en el siglo XVI.

50. Santiago Fernández, 2000: 33-46. Font de Villanueva, 2005: 335-36. 
de 1502 ordenaron luir todos los censales cargados sobre la Diputación propiedad de catalanes, un $62 \%$ de los cuales habían sido extinguidos ya en I5II. Un segundo ciclo de represalias estalló en I5OI al reclamar algunos catalanes ciertas pensiones de censales al municipio de Fraga, y años después a Barbastro, Benabarre y Estopiñán. Desde 1525, se generó un intercambio de represalias entre Aragón y Cataluña que contrajo aún más el comercio y redujo los ingresos aduaneros de la Diputación. Tras ver fracasar sus intentos de mediación y constatar la poca implicación de Carlos $\mathrm{V}$ en el conflicto, la Diputación de Aragón adquirió en 1532 los censales en disputa, pese a estimar su legalidad dudosa, y realizó un mayor esfuerzo económico que la Diputación o Generalitat de Cataluña para compensar a los damnificados con el fin de restablecer el comercio ${ }^{51}$.

Sin embargo, amén del rigor de sus guardas aduaneros ante el menor desacuerdo arancelario ${ }^{52}$, los aragoneses siguieron sufriendo represalias en Cataluña en la década de los treinta del siglo XVI. Junto a su eficiencia para percibir deudas con menores costes y demoras para el acreedor, su continuidad vino motivada por el interés catalán en entorpecer las transacciones de Aragón, máxime al generar estas una balanza comercial positiva con Cataluña, como la Diputación reconoció en $1532^{53}$. Este saldo favorable para Aragón se debería tanto al aumento de las exportaciones de materias primas hacia Cataluña como a la consolidación de una manufactura textil autóctona que habría reducido las importaciones de tejidos catalanes ${ }^{54}$. Ubicado Aragón en el interior de la península ibérica, las represalias catalanas dificultaban la navegación del Ebro y el acceso a puertos mediterráneos por parte de comerciantes regnícolas y beneficiaban el control catalán sobre la comercialización de materias primas aragonesas como la lana, principal mercancía incautada. Con el fin de proteger a su pujante burguesía mercantil5, la Diputación desde I533 indemnizó a todo mercader que hubiera sufrido represalias a cambio de su renuncia a toda acción similar hasta erradicar este problema en $154 \mathrm{O}^{56}$.

Cuando la Diputación luchaba por extinguir las últimas represalias, otro litigio enturbió el comercio entre Aragón y Cataluña. A raíz de las quejas cursadas por la Diputación el mes anterior, la Generalitat le comunicó en enero de 1536 la aplicación de un acto de corte aprobado por las Cortes catalanas en el pasado que permitía gravar toda moneda para gastos de viaje que los aragoneses extrajesen del principado con un $5 \%$ de su valor como si fuera mercancía, a diferencia de la exención disfrutada por los viajeros de las demás naciones ${ }^{57}$. Dicha decisión había venido motivada por el arancel del 2,5\% sobre la exportación de ducados y escudos -el florín se hallaba exento- impuesto en Aragón a naturales y extranjeros, que incluía la moneda destinada a gastos de viaje y considerada de propio uso, para limitar la salida de ambas piezas de oro del territorio.

51. Sesma Muñoz, 1982: 211-30, 397-99, 420-22, 435-36, 455-60. Mateos Royo, 2019: 291-322.

2. ADPZ, ADR, Ms. 141, f. 49r-v.

53. ADPZ, ADR, Ms. 143, f. 82r.

54. Desportes BIELSA, 1999: 192-209, 257-68.

55. Sobre esta burguesía, Gómez ZORRAQUino, 1985: 87-98.

56. ADPZ, ADR, Ms. 144, f. $45 \mathrm{v}-48 \mathrm{v}$.

57. ADPZ, ADR, Ms. 146, f. 49r-v, 53r-v 
La intromisión de la Generalitat en la política comercial de un reino vecino obedecía a su preocupación por la insuficiente oferta de piezas de oro en Cataluña. Esta carencia se veía favorecida no sólo por el escaso número de ducados o principats fabricados en la ceca de Barcelona entre I53I y 1575, sino por su creciente exportación ante su mayor valor intrínseco frente a los escudos que comenzaron a fabricarse en Francia y el norte de Italia (Génova, Milán, Venecia, Florencia) durante el primer tercio del siglo $\mathrm{XVI}^{58}$. Como sucedía con los castellanos, muchos ducados catalanes serían reacuñados como escudos en las cecas de Francia con importantes beneficios tras ser atraídos por su mayor cotización en el mercado frente al escudo francés, dotado de un valor oficial superior al intrínseco desde los inicios del reinado de Francisco I (1515-1547) con este fin ${ }^{59}$. El interés de las instituciones catalanas por emitir piezas de oro con alto valor intrínseco para su uso en el comercio exterior durante el siglo XVI se refleja en la paulatina relegación de la emisión de ducados sencillos por la ceca de Barcelona frente a la acuñación de dobles ducados: iniciada en I534-I538 y consolidada en I560-I578, unida en este último período a la fabricación de piezas de a cuatro, diez y veinte ducados ${ }^{60}$. Al sufrir Cataluña periódicas carencias de piezas de oro debido a esta política monetaria, la Generalitat intentó en I535 mediante su presión arancelaria obtener para el principado una importación más barata de los ducados y escudos circulantes por Aragón.

Consciente de la posición de fuerza ganada por la Generalitat en el segundo ciclo de represalias, la Diputación adujo inútilmente en 1536 que dicho arancel databa de tiempo inmemorial y era reducido como cortesía a un I,375\% ó I, $83 \%$ en la moneda dedicada a gastos de viaje. Si la exportación de ducados estaba prohibida y la de reales restringida a los gastos de viaje en los reinos de Castilla, añadía, en Aragón la salida de piezas de oro era libre y la de moneda de plata se hallaba incluso exenta de aranceles con independencia de su uso ${ }^{6 .}$. Otras medidas comerciales vigentes en Aragón que favorecían el tránsito de piezas de plata y vellón de calidad hacia Cataluña tampoco detuvieron el conflicto aduanero. La excepcional prohibición de exportar reales, medios reales y toda moneda de plata de Aragón dictada por la Diputación en mayo de I535, posible causa adicional del litigio, había excluido las destinadas a gastos de viaje ${ }^{62}$. Las sucesivas vedas de extraer moneda jaquesa de vellón (dineros y miajas) de Aragón fijadas por dicha institución al arrendar los derechos aduaneros en vigor entre 1528 y 1536 exceptuaron las zonas de Cataluña donde eran utilizadas con asiduidad ${ }^{63}$.

58. Como ejemplo, CIPOLLA, 1994: 24-29. Las Cortes catalanas lamentaban ya en 1533 la exportación de ducados hacia Francia. Véase Carrera PujaL, 1943-47, t. II: 256.

59. CARANDE, 1949-67, vol. III: 229. Los beneficios de fundir ducados castellanos para emitir escudos franceses alcanzarían entre un 40\% y 50\% del valor de la emisión, según RUIz TRAPERO, 1990: 227-28.

6o. Sanahuja Anguera, 2013: 438-39, 444-45, 448-49, 451-53.

61. ADPZ, ADR, Ms. 141, f. 53r-v.

62. ADPZ, ADR, Ms. 141, f. 9v-1or. Las Cortes catalanas de 1533 y 1537 se quejaron de la carestía de moneda de plata en el principado no solo debido a su exportación, sino a su fundición y reacuñación ilegal con menor valor intrínseco. Para combatir estas prácticas, las Cortes de 1537 debatieron la opción de acuñar croats rebajados de peso. Pese a reconocer esta escasez, el Consejo de Ciento de Barcelona rechazó dicha reforma. Véase CARRERA PUJAL, 1943-47, t. II: 256-57. Sanahuja Anguera, 2013: 1062-63.

63. ADPZ, ADR, Ms. 124, f. 42v, Ms. 129; f. 95v, Ms. 143, f. 27r. Prueba de la pervivencia de esta práctica, el 
Esta medida adoptada en I535 por la Generalitat adquiría rasgos propios de una guerra arancelaria por cuanto resultaba discriminatoria al aplicarse en exclusiva a los aragoneses y carecía de proporcionalidad tanto al adoptar un arancel de salida del $5 \%$, superior al 2,5\% impuesto en Aragón al oro de propio uso, como al extenderlo a toda moneda de oro, plata o vellón destinada a este fin. Tras protestar contra dicha decisión por entorpecer el comercio entre ambos territorios, la Diputación indicó a la Generalitat que elevaría los derechos aduaneros cobrados a los catalanes en Aragón en idéntica medida a cómo ascendieran para los aragoneses en Cataluña ${ }^{64}$. Pese a todo, la Generalitat seguía exigiendo en 1539 este arancel incluso a las blancas castellanas de vellón que los aragoneses extraían de Cataluña para sus gastos de viaje ${ }^{65}$.

Arzobispo de Zaragoza y virrey de Cataluña, Fadrique de Portugal Noreña presentó a los brazos de las Cortes catalanas en 1537 una doble solución: prohibir toda represalia entre Aragón y Cataluña y aplicar una exención arancelaria para toda moneda de uso propio que los habitantes de un territorio exportasen del otro. Esta propuesta fue remitida para su examen a la veinticuatrena, comisión parlamentaria dependiente del Consejo municipal de Ciento de Barcelona formada por ocho miembros por cada brazo de ciudadanos, mercaderes y estado llano. Aportación propia, dicho organismo aconsejó que la ampliación a los aragoneses de los mismos aranceles sobre la salida de moneda impuestos a los restantes extranjeros en Cataluña requiriese que estos fueran aplicados a los catalanes en Aragón en vez de los usuales allí cobrados a naturales y extranjeros ${ }^{66}$.

Ante la falta de acuerdo, la pugna arancelaria prosiguió en claro perjuicio de los aragoneses. Única respuesta constatada, la Diputación acordó en el contrato trianual suscrito con los arrendatarios de los derechos aduaneros en mayo de 1545 introducir un arancel del 5\% sobre las blancas de vellón que los catalanes exportasen del reino a partir de enero de I546. Dichas piezas habían estado exentas en el pasado por dedicarse al propio uso. Una cláusula del contrato especificó que la Diputación podía levantar este gravamen en cuanto la Generalitat de Cataluña eliminase todo arancel discriminatorio sobre los aragoneses ${ }^{67}$. Su imposición exclusiva al vellón castellano se atenía a la legislación de las Cortes aragonesas, que permitía gravar con un $5 \%$ todo producto cuyo arancel no fuera regulado por actos de corte ${ }^{68}$. Respetaba así los aranceles tradicionales en Aragón sobre la salida de oro y plata, obviando elevarlos para los catalanes en idéntica proporción a como se aplicaban a los aragoneses en el principado.

\footnotetext{
municipio de Lérida decidió en 1556 adquirir moneda jaquesa y permitir su uso en dicha ciudad para paliar la carencia de vellón catalán. Véase SANAHUJA ANGUERA, 2013: 1072-73.

64. ADPZ, ADR, Ms. 141, f. 53r-v.

65. ADPZ, ADR, Ms. 146, f. 49r-v.

66. Carrera Pujal, 1943-47, t. II: 403.

67. ADPZ, ADR, Ms. 154, f. 44r-v.

68. Ibíd.
} 


\section{LA EXTINCIÓN DEL CONFLICTO ADUANERO ENTRE ARAGÓN Y CATALUÑA: LAS REFORMAS ARANCELARIAS DE 1547 Y 1564}

Una comisión formada por miembros de los cuatro brazos representados en las Cortes aragonesas de 1547 elaboró una propuesta de concordia entre Aragón y Cataluña destinada a solucionar el conflicto, aprobada por esta asamblea en diciembre. De acuerdo con la exención arancelaria concedida a los bienes de propio uso de naturales y extranjeros aprobada por dichas Cortes ese año ${ }^{69}$, la concordia detalló las propiedades de catalanes que resultaban exentas de arancel para eliminar dudas sobre si se trataba de bienes personales en las aduanas. Ofrecieron así a los catalanes la libre entrada y salida en Aragón de sus caballos y todo tipo de bestias de montar, perros y aves de muestra, caza y cetrería, vasos de oro y plata, joyas, vestidos, libros, armas, tapices, guadamecíes, alimentos y todo bien para uso propio. La cantidad de moneda destinada a sufragar el viaje, estimada según la calidad del viajero y la distancia recorrida entre la frontera y su destino, se vería libre de todo arancel. Los demás bienes, considerados mercancías, pagarían los mismos derechos de entrada y salida en Aragón que los aragoneses en Cataluña, quedando pendiente de discusión el arancel común. Los catalanes podían recurrir las decisiones de los guardas aduaneros ante la Diputación en Zaragoza o a los Justicias locales en los restantes lugares y aún apelar a la Diputación si sus mercancías valían más de I.ooo sueldos jaqueses. La validez de esta ley requería que las Cortes de Cataluña otorgaran idénticas concesiones a los aragoneses ${ }^{70}$.

Amén de extinguir las causas del desacuerdo, esta ambiciosa reforma arancelaria buscaría promover las transacciones y actividades productivas orientadas a la exportación en Aragón cuando ambas alcanzaban su período de mayor expansión, según refleja el fuerte aumento de los ingresos aduaneros de la Diputación acaecido entre 1537 y 1569 -véase el Gráfico I-. E intentaría paliar algunos trastornos sufridos por el comercio aragonés a mediados del siglo XVl. Entre estos, se contarían los generados por las órdenes dictadas por el virrey de Aragón que prohibían intercambiar mercancías con Francia al entrar en guerra con España (I542-I544, I552-59), restricciones limitadas en anteriores conflictos (I52I-I529, I536-I538) a la exportación de caballos y material bélico ${ }^{71}$. También las prohibiciones de exportar trigo y reses de Aragón dictadas año tras año por la Diputación desde 1556 para favorecer el abasto de la población pese a reducir sus ingresos aduaneros, mantenidas durante el resto del siglo XVI y varias décadas de la centuria siguiente ${ }^{72}$.

Pese a las ventajas que ofrecía la exención detallada de muchos bienes de propio uso -incluida la moneda-para reducir pagos de aranceles y litigios aduaneros, las Cortes de Cataluña no aceptaron esta concordia. Las causas obedecieron

\footnotetext{
69. Savall y Dronda \& Penén Debesa, 1866, vol. I: 203.

70. ACA, CA, Cancillería, Procesos de Corte, 46, Registro de las Cortes de 1547, f. 407r-408v.

71. ADPZ, ADR, Ms. 144, f. 38r-39r, Ms. 683, f. 20r-v, Ms. 688, f. 55r-56v, 62r-66r, Ms. 689, f. 58r-62v. y CoLAS LATORRE Y SALAS Ausens, 1982: 208-27, 443-46.

72. Sobre el tema, para la segunda mitad del siglo XVI, véase ADPZ, ADR, Ms. 23, 176, 180, 184, 185, 188, 193, 199, 201, 210, 217, 221, 230, 231, 238, 244, 245, 248, 251, 254, 258, 263, 276, 280, 286 y 692.
} 
probablemente a las dificultades para homogeneizar todos los derechos aduaneros sobre las mercancías, bastante dispares -el arancel medio en Aragón era un 5\% mientras que en Cataluña era un I,7\%-, así como cobrarlos en exclusiva a aragoneses y catalanes. Sin embargo, ambas Cortes igualaron en 1547 los aranceles y exenciones que afectaban a las piezas de oro y plata extraídas de un territorio por parte de los «vecinos y habitantes» del otro mediante normas susceptibles de ser revisadas por futuras Cortes. Como la veinticuatrena propuso en I537, el gravamen mutuo para las monedas de oro y plata exportadas con fines comerciales se fijó en el 5\% de su valor, el habitual en Cataluña. Una cláusula añadida en la década siguiente precisó que los lugartenientes generales de Cataluña y Aragón quedaban exentos de este tributo al extraer plata de su propiedad con independencia de la cuantía. Por último, las monedas de ambas especies destinadas a costes del viaje eran consideradas de propio uso y libres de todo arancel. La estimación de dichos costes consideraría los gastos del viajero y sus acompañantes en función de su status social y la duración del trayecto desde la frontera a su destino ${ }^{73}$.

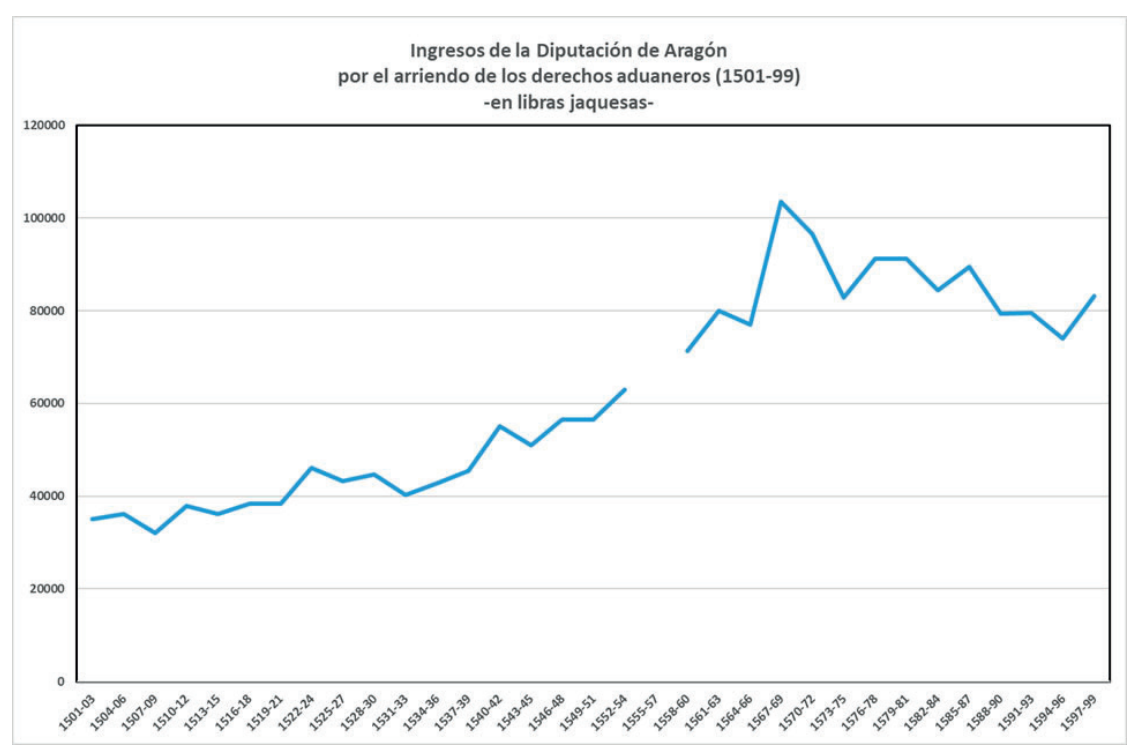

fuentes: Colas Latorre \& Salas Ausens, 1982: 43. Gómez Zorraquino, 1985: 89

Nota: Para los años 1567-1569, 1570-1572, 1576-1578, 1579-1581 y 1585-1587, se ha deducido el monto de los diversos pagos adicionales asumidos por los arrendatarios que, sumados al precio inicial de arriendo, conforman su precio final tomando como referencia los trienios de 1564-1566, 1573-1575 y 1588-1590, en que se dispone de ambos datos

73. ADPZ, ADR, Ms. 686, f.41v, Ms. 176, f.133r, Ms. 184, f. 136v, Ms. 188, f. 283v-284r. Este acuerdo se recoge en los contratos de arriendo de los derechos aduaneros firmados por la Diputación entre 1548 y 1563 como acto de corte entre los estamentos de las Cortes aragonesas y catalanas celebradas en 1547. Sin embargo, no figura como tal en las Actas de las Cortes aragonesas de 1547 conservadas en ACA, CA, Cancillería, Procesos de Corte, 46. Quizás su negociación fue confiada a delegaciones de ambas Cortes con poderes decisorios, que culminarían dicho convenio una vez que estas habían sido ya clausuradas. 
Los términos de esta reforma despiertan consideraciones de interés. Al tiempo que rechazaron dos proyectos de ley para devaluar o «subir» su moneda autóctona ${ }^{74}$, medida que habría frenado su exportación, las Cortes catalanas de 1547 prefirieron conseguir para sus vecinos y habitantes la exención de los ducados y escudos destinados a gastos de viaje en las aduanas aragonesas a costa de elevar los aranceles de salida allí aplicados a las monedas de oro y plata exportadas con fines comerciales. Esta decisión parece indicar que, pese a las escasas emisiones de croats efectuadas en Cataluña bajo Carlos V y las quejas de sus Cortes en I533 y I537 sobre la exportación y escasez de piezas de plata, su carencia no era tan grande como para impulsar la llegada de reales desde Aragón con medidas arancelarias. La explicación podría deberse a la pervivencia parcial del real catalán o croat allí acuñado en reinados anteriores, favorecida por su menor valor intrínseco que el real castellano o aragonés al contar con una ley superior de II dineros y 6 granos; pero un peso de sólo 3,25 gramos. Las piezas castellanas de plata más demandadas en Cataluña durante el siglo XVI habrían sido los reales de a dos, cuatro y ocho, dedicados al comercio exterior mediante su exportación legal o ilegal. Así lo evidencia que la ceca de Barcelona sólo fabricase croats sencillos entre I545 y 1598 destinados al mercado interno, conforme más reales castellanos y sus múltiplos llegaron al principado desde mediados de la centuria ${ }^{75}$.

Aceptada por las Cortes aragonesas en detrimento de la soberanía arancelaria del reino para cancelar el litigio aduanero, esta reforma alteraba su política tradicional de moderar los derechos percibidos sobre la salida de moneda de oro y plata; pero gravar toda extracción de ducados y escudos para favorecer su permanencia en Aragón. Las Cortes tuvieron que confiar en que el nuevo arancel del $5 \%$ sobre las piezas de oro exportadas con fines comerciales contuviera su salida hacia Cataluña y desde allí hacia Francia, cuya importación del oro circulante por Aragón en moneda y barras era bien conocida por sus Cortes y Diputación a mediados de los años cuarenta del siglo $\mathrm{XVI}^{76}$. Como contrapartida comercial, la extensión a Aragón en 1547 del arancel del $5 \%$ sobre la salida de piezas de oro y plata ya usual en el principado favorecería que los mercaderes catalanes aumentasen prácticas ya asentadas desde la Baja Edad Media de adquirir materias primas aragonesas como cereales y lana en vez de retornar a Cataluña con piezas de oro y plata que excedieran los costes de viaje ${ }^{77}$.

Estas condiciones se vieron modificadas al celebrarse las Cortes de la Corona de Aragón en 1563-1564, al ofrecer las Cortes aragonesas a las catalanas una nueva reforma que regulaba el procedimiento aduanero sobre los bienes de propio uso a la vez que modificaba los aranceles sobre la exportación de moneda fijados en $1547^{78}$. Respecto al primer punto, la nueva concordia concedía la misma exención de derechos de entrada y salida para bienes de propio uso planteada en I547; pero añadía una cláusula

74. Carrera Pujal, 1943-47, t. II: 256-57. Como hizo con la rebaja de peso del croat planteada en las Cortes de 1537, el Consejo municipal de Ciento de Barcelona también desestimó esta reforma con el argumento de que dicha devaluación sería ineficaz al imitarse en otros territorios.

75. Sanahuja Anguera, 2013: 453-66. Gil Farrés, 1958: 66. Crusafont y Sabater, 1996: 106. Sobre la escasez de moneda de plata en Cataluña denunciada por sus Cortes en 1533 y 1537, véase la nota 62.

76. ADPZ, ADR, Ms. 154, f. 43v. Savall y Dronda \& PenÉn Debesa, 1866, vol. II: 352.

77. SESMA MUÑOZ, 1977: 205, 223.

78. ADPZ, ADR, Ms. 190, f. 226v-228r. 
que permitía a los criados, factores y trajineros obtenerla como representantes de un particular si juraban ante los guardas aduaneros que los bienes por ellos transportados eran de propio uso de este y si disponían de un poder notarial para actuar en su nombre. De manera realista, las Cortes aragonesas omitieron la armonización arancelaria sobre las mercancías intercambiadas entre Aragón y Cataluña planteada en la propuesta de 1547 y se limitaron a revisar los derechos de salida para las piezas de oro y plata acordados ese año. Como se había pactado en la reforma arancelaria de 1547, los escudos o ducados de oro que los catalanes exportasen de Aragón para sus gastos de viaje quedaba libres de arancel, considerando el status del viajero, el número de sus acompañantes y la duración del viaje. Sin embargo, la extracción de moneda de oro con fines comerciales desde Aragón por parte de catalanes hacia el principado debía abonar el impuesto usual del 2,5\% mientras que la salida de toda moneda de plata quedaba exenta de gravamen. Para dar validez a la concordia, las Cortes aragonesas de 1564 exigieron idénticas concesiones a las ofrecidas, aprobadas por las Cortes catalanas ese mismo año. Prueba de la buena sintonía alcanzada, al comprometerse la Diputación ante la Generalitat en febrero de 1565 a poner en práctica este acuerdo, ofreció incluir en sus términos a la blanca castellana de vellón que los catalanes extraían de Aragón no sólo de camino a Cataluña, sino a los reinos de Castilla $\mathrm{u}$ otros extranjeros ${ }^{79}$.

Si la exención arancelaria sobre bienes de propio uso acordada en 1564 agradaba a los estamentos privilegiados y restantes grupos sociales acomodados de Cataluña y Aragón por cuanto incluía objetos y animales que representaban su alto status social, la rebaja de los derechos tocantes a la exportación de moneda de oro y plata favorecía los intereses de sus grupos mercantiles y financieros. Las Cortes aragonesas efectuaron esta propuesta cuando la burguesía mercantil autóctona había consolidado su auge ${ }^{80}$ y los ingresos aduaneros de la Diputación alcanzaban sus máximos durante el siglo XVI, como muestra el gráfico I. Las Cortes de Cataluña la recibieron cuando su burguesía, conforme amplió sus actividades mercantiles y financieras desde mediados de siglo ${ }^{81}$, demandó más moneda castellana de plata y en especial múltiplos de real cuyos bajos precios relativos en el mercado catalán tornaban rentable su compra y exportación. El Consejo municipal de Ciento ordenó así en I553 a la Tabla de Cambios de Barcelona aceptar al mismo precio de 24 dineros los croats catalanes y los reales castellanos y aragoneses. Esta homologación del valor oficial en vellón de las tres monedas de plata pese al mayor valor intrínseco de los reales castellanos y aragoneses parece indicar que ambos sufrían recortes más frecuentes en sus bordes que los croats debido a su mayor peso; pero la demanda del mercado forzaba su utilización pese a estar cercenados. Con el preceptivo permiso de la monarquía hispánica, dicho Consejo de Ciento logró fundir en I578 y I595-1596 reales castellanos en la ceca de Barcelona para fabricar croats destinados al mercado interno, obteniendo así beneficios de su emisión ${ }^{82}$.

79. ADPZ, ADR, Ms. 193, f. 79r-v.

80. Gómez ZorRaQUiNo, 1985: 25-131.

81. HERNÁNDEZ, 1997

82. Sanahuja Anguera, 2013: 462-64, 1067, 1083-90. Carrera Pujal, 1943-47, t. II: 258. Los frecuentes cercenes 
En suma, Aragón y Cataluña buscarían fomentar el comercio mutuo y agilizar la movilidad del capital mercantil de un territorio a otro, en especial de las piezas de plata, beneficiadas por una mayor reducción arancelaria. Aragón incluía a los catalanes en su política arancelaria tradicional sobre la salida de moneda de oro y plata para uso comercial, manteniendo la exención pactada sobre los ducados y escudos para propio uso. Cataluña concedía a los aragoneses una reducción excepcional del arancel de exportación del $5 \%$ sobre ambas monedas cargado a naturales y extranjeros. Esta idea de facilitar el tránsito transfronterizo de numerario mediante rebajas arancelarias presente en la concordia de 1564 llevó a las Cortes catalanas en 1585 a reducir del $5 \%$ al $2,5 \%$ la tarifa sobre la salida de moneda impuesta a todo viajero, tanto natural como extranjero. Con todo, dichas Cortes la repusieron en el $5 \%$ en I599, probablemente tras constatar que favorecía en exceso su exportación hacia Francia e Italia ${ }^{83}$.

\section{CIRCULACIÓN MONETARIA, ACTIVIDAD FINANCIERA Y COMERCIO EXTERIOR EN ARAGÓN Y CATALUÑA (1565-1600)}

Resulta muy complejo medir las consecuencias de la reforma arancelaria adoptada en I564 sobre la circulación de piezas de oro y plata en Aragón y Cataluña durante el último tercio del siglo XVI ante la carencia de fuentes que permitan cuantificar la oferta monetaria de ambos territorios antes y después de dicha reforma. Pese a estas dificultades, considero útil exponer ciertos cambios apreciados en los flujos monetarios, las actividades financieras y las transacciones exteriores de ambos territorios en este período. Su consideración permitirá valorar de forma aproximada tanto la influencia de esta reforma sobre dichos procesos económicos como la incidencia conjunta de todos estos sobre la capacidad de atracción y retención de piezas de oro y plata.

En primer lugar, cada vez más condicionada la circulación monetaria en la Corona de Aragón por el déficit comercial y financiero de Castilla ${ }^{84}$, los cambios en las rutas utilizadas para desplazar los escudos y reales allí emitidos potenciaron su tránsito a través de Aragón y Cataluña en el último tercio del siglo XVI, rumbo a Francia e Italia. Obstaculizada la ruta marítima atlántica por los piratas ingleses y holandeses en 1568-1569 y la terrestre francesa por las guerras de religión desde 1578, las remesas de oro y plata destinadas por Felipe Il a sofocar la rebelión de los Países Bajos se dirigieron ya desde la década de 1570 a Italia por vía marítima. Una de estas rutas cruzaba Aragón hacia Barcelona, Rosas y Tarragona para alcanzar desde estos puertos Génova y el norte de Italia ${ }^{85}$. Los mercaderes-banqueros de Génova,

\footnotetext{
de la moneda de plata que retornaba a Cataluña tras su exportación llevaron al Consejo de Ciento a plantearse en 1567 aceptar estas piezas a peso en la Tabla de Cambios de Barcelona. De forma probable, parte de estos reales recortados en circulación serían fundidos para la acuñación de croats.

83. HERNÁNDEZ, 2003: 169

84. Véase la nota 29.

85. Vilar, 1974: 209-12. Ruiz Martín, 1990: 85-86.
} 
Milán y Florencia convertían en las ferias de Besançon o Plasencia mediante letras de cambio parte de los reales enviados en escudos, exigidos como pago por los ejércitos de Felipe $\mathrm{II}^{86}$. La necesidad de liquidez y la apreciación del real castellano por su alto valor intrínseco en los mercados europeos propició la creciente absorción de esta moneda de propiedad pública y privada exportada hacia Italia a través de la ruta citada o hacia Francia, cruzando las fronteras terrestres de Aragón y Cataluña o el mar mediterráneo. Una parte de estas monedas eran reacuñadas en las cecas de Francia, Italia y Holanda con menor peso y ley para su utilización en el comercio interior ${ }^{87}$. Las piezas con mayor contenido argentífero, como el real de a ocho, se reservaron para el comercio exterior y resultaron de gran utilidad en los territorios que bordeaban el mediterráneo orienta ${ }^{88}$ en su tránsito hacia Asia. Este destino final vino motivado por la fuerte demanda de plata realizada por China desde 1570 para su comercio interno, que había depreciado allí el valor del oro frente a la plata a la mitad de su cotización en Europa ya entre 1585 y I60o, generando flujos de oro desde Asia hacia Europa donde su poder adquisitivo era más elevado ${ }^{89}$.

En segundo término, Cataluña disponía en Barcelona de amplios grupos de mercaderes y banqueros catalanes, castellanos, genoveses y otros extranjeros preparados para gestionar estos mayores flujos de capital público y privado. En el último tercio del siglo XVI, dichos grupos se beneficiaron de la fuerte demanda de sus servicios realizada por la monarquía hispánica: créditos, envíos de materias primas, alimentos y pertrechos a galeras y guarniciones o traslados de moneda a Italia para pagar a los ejércitos españoles. Sus distintas actividades incluían la exportación ilegal de reales castellanos de propiedad privada hacia Francia e Italia, para aprovechar su mayor cotización que en España ${ }^{90}$. En contraste, la menor actividad mercantil y financiera de Aragón resultó condicionada por la extinción de la burguesía autóctona hacia 1580 y su sustitución por mercaderes genoveses hasta su quiebra en I620 ${ }^{91}$. Asentados en Zaragoza desde 1560, estos mercaderes estrecharon sus vínculos con las colonias mercantiles genovesas de Barcelona y Madrid e incluso con mercaderes catalanes de Barcelona al actuar como sus representantes ${ }^{92}$. Sin desdeñar la exportación a Cataluña de escudos de oro traídos desde Castilla, utilizando a veces cédulas reales que los eximían de aranceles aduaneros como propiedad del monarca ${ }^{93}$,

86. Ruiz Martín, 1990: 31-43. Boyer-Xambeau, Deleplace \& Gillard, 1991: 313-44. Parker, 1976: 194-96. Sobre la clara pérdida de poder de compra para la monarquía española en Flandes resultante de tener que transformar en oro la plata allí utilizada durante el último tercio del siglo XVI, YUN, 2004: 331-332.

87. Como ejemplo, véase el caso de Florencia en CIPOLLA, 1994: 90-92.

88. Martín Corrales, 2000.

89. Chaudhuri, 1984: 58-60. Flynn \& Giráldez, 2000: 390-94. García Guerra, 2006: 246-48.

90. Ruiz Martín, 1975. HeRnÁndeZ, 1997a: 58-64. 1997b: 29-34.

91. Gómez Zorraquino, 1985: 216-19. 1995. El transporte de piezas de oro y plata desde Castilla a Italia por los mercaderes-banqueros genoveses asentados en España se vio facilitado por su hegemonía como prestamistas de la monarquía entre 1577 y 1627, que les facilitaba obtener las licencias reales de exportación. Sobre el tema, véase DE Carlos Morales, 1999; 2013.

92. García ESPUCHE, 1998: 377-82. El auge de la colonia mercantil catalana en Zaragoza sólo se produjo desde 1600 ante la consolidación del comercio entre Barcelona y Madrid, potenciado por la demanda de mercancías catalanas por parte de la Corte y la propia capital. Este comercio generaba un importante flujo de moneda desde Madrid a Barcelona en la década de 1620 .

93. ADPZ, ADR, Ms. 205, f. 92v-93v, 128r-133r. 
dichos mercaderes aprovecharon sus contactos para trasladar reales desde Zaragoza a Barcelona, y de allí a Italia. Como extranjeros naturalizados, los comerciantes genoveses asentados en Aragón y Cataluña se sirvieron de las rebajas arancelarias acordadas en 1564 para realizar este tráfico de piezas de plata con menores costes y controles aduaneros que si lo efectuasen a través de otros territorios ${ }^{94}$.

En tercer lugar, pese a carecerse de estimaciones cuantitativas y cualitativas sobre la balanza comercial entre Aragón y Cataluña en el último tercio del siglo XVI, se puede afirmar que las rebajas arancelarias sobre la salida de moneda aprobadas en I564 no incentivaron las transacciones mutuas lo suficiente para evitar el declive del comercio exterior en ambos territorios, hecho que limitó la acumulación de capital mercantil. Más fragmentarios en el caso de Cataluña, los datos procedentes de la tabla de Barcelona para el período I563-1587 reflejan en I584-I587 una brusca caída de los ingresos aduaneros de la Generalitat tras su auge en 1572-I57895. Más regular y constante, la información disponible para Aragón asociada al arriendo de los derechos aduaneros cobrados en todas las tablas de dicho reino revela un declive más temprano y gradual: tras los máximos de 1567-1572, los ingresos aduaneros descendieron con algunos altibajos el resto de la centuria -véase el gráfico I-. Esta contracción del comercio exterior se ha vinculado en Aragón a la restricción de las exportaciones ligada a limitaciones de la propia producción agraria ante la mayor frecuencia de malas cosechas y la interrupción de intercambios motivada por conflictos políticos o sociales externos -guerras de religión en Francia- e internos: oposición y rebelión forales frente a la autoridad real, levantamientos antiseñoriales y bandolerismo ${ }^{96}$. El comercio exterior catalán también se resintió del estallido de estas guerras civiles en Francia, así como de las luchas entre nobles o el bandidaje que sacudían el principado ${ }^{97}$.

Insuficiente para reactivar el comercio exterior y propiciar la retención de capital, la reforma de 1564 habría facilitado así al reducir aranceles y trabas aduaneras la fuga de piezas de oro y plata desde Castilla a Aragón y Cataluña y desde allí a Francia e Italia, ya consolidada por la propia demanda de los mercados europeos. Reflejo de esta realidad, las actuaciones de la Diputación de Aragón contra la extracción ilegal de piezas de oro hacia Cataluña y Francia por parte de mercaderes y otros particulares se recrudecieron desde 1570 al escasear más esta moneda en los mercados y constituir una evasión fiscal que mermaba sus ingresos ${ }^{98}$. Menos criticada por las autoridades públicas al no estar gravada con aranceles ni generar carestías, la salida de reales desde Aragón hacia Cataluña resultó constante ${ }^{99}$. Agudizada por

94. ADPZ, ADR, Ms. 245. f. 332r-v. Como ejemplo, la Diputación apeló a la concordia de 1564 para solicitar a la Generalitat en noviembre de 1582 que restituyese a Borbón Centurión, mercader genovés vecino de Zaragoza, 12.00o libras jaquesas de plata que remitió a Barcelona como pago al mercader genovés Benito Lomelino. Incautadas en Lérida a un criado de Centurión por no declararlas a los guardas aduaneros, la Diputación basó su petición en que dichas monedas no estaban sujetas al pago de arancel.

95. HERNÁNDEZ, 2003: 182. Recuérdese que estas cifras omiten las numerosas mercancías y monedas exportadas de Cataluña como bienes reales, libres de aranceles, durante el último tercio del siglo XVI.

96. Colas Latorre \& Salas Ausens, 1982: 42-46. Gómez Zorraquino, 1985: 89-90.

97. PÉrez LATre, 2004: 82-85. Sobre el tema, véase TORRES I SANS, 1993.

98. Véase las notas 33,34 y 35 .

99. Véase las notas 94,101 y 102. 
sus mayores nexos comerciales y financieros con Francia e Italia, la cotización de las piezas de oro y plata se elevó en Cataluña desde mediados del siglo XVI (como revelan los premios ofrecidos por banqueros y cambistas privados por el uso de monedas de ambas especies como medio de pago o el cercén de la moneda argentífera) y la exportación de reales desde el principado hacia ambos destinos ganó especial intensidad en este período ${ }^{\text {Ioo }}$.

Por último, en este contexto monetario, comercial y financiero, el interés de las elites de Cataluña por mantener la reforma aduanera de 1564 es evidente. Las peticiones cursadas por la Generalitat ante la Diputación de restituir a catalanes bienes incautados o aranceles cobrados por la salida ilegal de piezas de plata por los guardas aduaneros de forma estimada injusta aluden así a la conveniencia de preservar la colaboración aduanera entre reino y principado ${ }^{\mathrm{IOI}}$. En mayo de ${ }^{5} 593$, la Generalitat se quejó incluso a la Diputación de que los arrendatarios y guardas aduaneros de Aragón exigían a los catalanes, en especial a embajadores de la Generalitat y otras personas principales, derechos indebidos sobre la plata, joyas y otros bienes ya usados o se excedían en su estimación sin rebajar su coste. Caso de no corregirse esta práctica, advertía, los viajeros aragoneses podían no hallar las «cortesías y comodidades» acostumbradas en su tránsito por Cataluña ${ }^{102}$. En aras de mantener esta cooperación, la Diputación de Aragón decidió en 1589 incluir los puntos de la concordia de 1564 en el nuevo arriendo de los derechos aduaneros, obviando que las Cortes aragonesas habían olvidado en 1585 por descuido renovar la concordia y hacerlo constar por escrito, como era preceptivo para asegurar su validez futura ${ }^{\mathrm{IO} 3}$. Desde su aceptación en 1564 , dichos términos fueron recogidos en todos los arriendos de dichos derechos suscritos por las Diputaciones de Cataluña y Aragón hasta la extinción de sus sistemas forales a principios del siglo XVIII ${ }^{104}$.

\section{CONCLUSIONES}

Como conclusiones, se aprecia que los conflictos y acuerdos arancelarios surgidos entre Aragón y Cataluña durante el segundo tercio del siglo XVI resultan ilustrativos de dos procesos sufridos por la circulación monetaria en el Nordeste español. El primero, común a toda Europa, es la demanda de mayor liquidez por parte de los mercados y la paralela apreciación de la moneda de oro frente a la de plata por su mayor escasez. El segundo, más peculiar de la Corona de Aragón, es la creciente dependencia de las piezas castellanas de oro y plata para practicar el comercio

100. Carrera Pujal, 1943-47, t. II: 258. Vilar, 1978, vol. I: 348-49. Sanahuja Anguera, 2013: 460-66.

101. ADPZ, ADR, Ms. 23, f. 47r-v, Ms. 238, f. 244r-246r, Ms.245. f.332r-v y Archivo Municipal de Zaragoza, Manuscrito 10, titulado Comentarios para la Historia de Aragón, desde el año 1615 hasta el año 1627, escrito por el cronista Bartolomé Leonardo de Argensola, impreso inserto tras f. 38 con el epígrafe «Viedas de la moneda de oro y plata por los señores diputados de Aragón», f. 10.

102. ADPZ, ADR, Ms. 263, f. 463 r.

103. ADPZ, ADR, Ms. 255, f. 370r-v.

104. Carrera Pujal, 1943-47, t. II: 404. 
ante el declive de las emisiones autóctonas, proceso acaecido con anterioridad en Aragón que en Cataluña.

El conflicto aduanero estudiado que enfrentó a Aragón y Cataluña vino precedido por dos ciclos de represalias entre I484 y 1540 que concluyeron aumentando la capacidad de presión sobre el comercio aragonés que podía ejercer la Generalitat frente a la Diputación. Basada en imponer a los aragoneses gravámenes discriminatorios y desproporcionados sobre toda moneda de propio uso, la guerra arancelaria desatada por la Generalitat en I535 buscó obtener para los catalanes la libre extracción de Aragón de escudos y ducados dedicados a gastos de viaje para paliar la escasez de piezas de oro en el principado. La resolución de este litigio resultó lenta y compleja ante la dificultad de armonizar dos políticas arancelarias distintas sobre la salida de monedas de oro y plata.

Como vía de solución del conflicto, las Cortes aragonesas enviaron en 1547 a las catalanas una propuesta que ofrecía tanto un amplio reconocimiento de los bienes de propio uso exentos -incluidas las piezas de oro exportadas- como una homogeneización arancelaria entre Aragón y Cataluña que facilitase el comercio mutuo. Rechazado este acuerdo, las Cortes catalanas lograron extender la aplicación de su política arancelaria sobre la exportación de moneda a los viajeros catalanes en Aragón. A cambio de suprimir los aranceles discriminatorios en Cataluña, las Cortes aragonesas elevaron a estos catalanes al $5 \%$ el gravamen de salida sobre las piezas de oro y plata destinadas a fines comerciales; pero les eximieron de todo arancel por las de propio uso. Su aceptación por estas Cortes, en detrimento de la política y soberanía arancelaria de Aragón, vino impuesta por la necesidad de poner fin al conflicto.

Ante la demanda de mayor liquidez y el creciente predominio de las piezas de plata sobre las de oro en los mercados, las Cortes aragonesas propusieron en I563I564 una nueva reforma arancelaria. Añadieron así a la exención de los bienes de propio uso ya ofrecida en 1547 el uso de representantes por su propietario, renunciaron a toda homogeneización arancelaria y mantuvieron la exención de la moneda de propio uso. A cambio, demandaron a las Cortes catalanas la supresión y rebaja al 2,5\% de los gravámenes respectivos sobre la salida de piezas de plata y oro con fines comerciales, política arancelaria usual en Aragón. Favorable a los grupos acomodados de ambos territorios, en especial a sus elites mercantiles y financieras al intentar potenciar la movilidad del capital y el comercio mutuos, este acuerdo fue aceptado por las Cortes catalanas en 1564 y perduró el resto de la época foral moderna. Incapaz de revertir el declive del comercio exterior en Aragón y Cataluña en el último tercio del siglo XVI, esta reforma de 1564 habría facilitado la exportación de numerario de oro y plata hacia Francia e Italia -potenciada por la propia demanda de los mercados europeos- al reducir aranceles y trabas aduaneras, perjudicando su retención en ambos territorios. 


\section{BIBLIOGRAFÍA}

Álvarez Nogal, Carlos, Los banqueros de Felipe IV y los metales preciosos americanos (I62II665), Madrid, Banco de España, I997.

ÁlvareZ NogaL, Carlos, «Los problemas del vellón en el siglo XVII. ¿Se consiguió abaratar la negociación del crédito imponiendo precios máximos a la plata?, Revista de Historia Económica, I9/I (200I): 17-37.

ANDRÉs UCENDO, José Ignacio, «La moneda de plata en Castilla durante la primera mitad del siglo XVII», Hispania, LIX/2 (1999): 533-45.

Beltrán Villagrasa, Pío, Obra completa, Zaragoza, Librería General, i972 (2 vols).

Bernal Rodríguez, Antonio-Miguel (ed.), Dinero, moneda y crédito en la monarquía hispánica, Madrid, Fundación ICO, 2000.

BLANCO LALINDE, Leonardo, La actuación parlamentaria de Aragón en el siglo XVI, Zaragoza, Cortes de Aragón, i996.

Boyer-Xambeau, M.T., Deleplace, G. \& Gillard, L., Banchieri e principi. Moneda e crédito nell' Europa del Cinquecento, Torino, Eunadi, I99I.

Carande, Ramón, Carlos Vy sus banqueros, Madrid, Sociedad de Estudios y Publicaciones, I949-1967 (3 vols).

Carrera Pujal, Jaime, Historia de la economía española, Barcelona, Bosch, I943-47 (5 tomos).

Castillo Pintado, Álvaro, «Dette flotante et dette consolidée en Espagne, I557 à I600», Annales. Economies, Societés, Civilisations, I963: 745-59.

Castillo Pintado, Álvaro, «Los juros de Castilla: apogeo y fin de un instrumento de crédito», Hispania, XXIII (1963): 43-70.

Cipolla, Carlo María, El gobierno de la moneda. Ensayos de Historia monetaria, Barcelona, Crítica, I994.

Colas Latorre, Gregorio \& Salas Ausens, José Antonio, Aragón en el siglo XVI. Alteraciones sociales y conflictos políticos, Zaragoza, Universidad, 1982.

Crusafont y Sabater, Miquel, «Los dineros jaqueses de la época de los Austrias y de Felipe V», en La moneda aragonesa, Zaragoza, Institución Fernando el Católico, I983: 22I-33.

Crusafont y Sabater, Miquel, Barcelona i la moneda catalana, Barcelona, Caixa de Pensions, I989.

Crusafont y Sabater, Miquel, Història de la moneda catalana, Barcelona, Crítica, 1996.

Chaudhuri, K.N. «Circuits monetaires internationaux, prix comparés et spécialisation économique, I500-I700», en John Day (ed.), Études d'histoire monetaire, Lille, Presses Universitaires, I984: 49-67.

De Carlos Morales, Carlos Javier, «La hacienda real de Castilla y la revolución financiera de los genoveses (I560-I575)», Chronica Nova, 26 (1999): 37-78.

De Carlos Morales, Carlos Javier, Felipe II: el Imperio en bancarrota. La hacienda real de Castilla y los negocios financieros del Rey prudente, Madrid, Dilema, 2008.

De Carlos Morales, Carlos Javier, «Endeudamiento dinástico y crisis financieras en tiempo de los Austrias: las suspensiones de pagos de I557-I627», Libros de la Corte.es, 7 (2013): 59-I28.

Desportes Bielsa, Pablo, La industria textil en Zaragoza en el siglo XVI, Zaragoza, Institución Fernando el Católico, 1999.

Domínguez Ortiz, Antonio, Política y hacienda de Felipe IV, Madrid, Editorial de Derecho Financiero, 1960. 
Domínguez Ortiz, Antonio, Crisis y decadencia en la España de los Austrias, Barcelona, Ariel, I973.

FlynN, Dennis O. \& GirÁldez, Arturo, «Imperial Monetary Policy in Global Perspective», en Antonio-Miguel Bernal Rodríguez (ed.), Dinero, moneda y crédito en la monarquía hispánica, Madrid, Fundación ICO, 2000: 385-403.

Font de Villanueva, Cecilia, «Política monetaria y política fiscal en Castilla en el siglo XVII. Un siglo de inestabilidades» Revista de Historia Económica, 23/I (2005): 329-47.

Font de Villanueva, Cecilia, La estabilización monetaria de I680-I686. Pensamiento y política económica, Madrid, Banco de España, 2008.

FONTECHA Y SÁNCHEZ, Ramón, La moneda de vellón y cobre de la Monarquía española (I5I6 a I93I), Madrid, Artes Gráficas, I968.

García Espuche, Albert, Un siglo decisivo. Barcelona y Cataluña, I550-I640, Madrid, Alianza, I998.

García Guerra, Elena María, Las acuñaciones de moneda de vellón durante el reinado de Felipe III, Madrid, Banco de España, I999.

GARcía GuERrA, Elena María, Las alteraciones monetarias en Europa durante la Edad Moderna, Madrid, Arco Libros, 2000.

García Guerra, Elena María, Moneda y arbitrios. Consideraciones del siglo XVII, Madrid, CSIC, 2003.

GArcía Guerra, Elena María, «Itinerarios mundiales de una moneda supranacional: el real de a ocho o peso durante la Edad Moderna», Studia Histórica. Historia Moderna, 28 (2006): 24I-57.

García De PAso, José Ignacio, «La estabilización monetaria en Castilla bajo Carlos II», Revista de Historia Económica, XVII//I (2000): 49-77.

GIL FARrÉs, Octavio, «La evolución de la moneda barcelonesa en los tiempos modernos», Numisma, 30 (1958): 53-68.

Gil FARrés, Octavio, Historia de la moneda española, Madrid, Adrados, i976.

Gómez ZorRaQUino, José Ignacio, La burguesía mercantil en el Aragón de los siglos XVI y XVII (I5I6-I652), Zaragoza, Diputación General de Aragón, I985.

Gómez ZorRaQuino, José Ignacio, «La colonia mercantil genovesa en Aragón (I580-I620)», en Homenaje a Don Antonio Durán Gudiol, Huesca, Instituto de Estudios Altoaragoneses, I995: 399-4I8.

Glassman, Debra \& Redish, Angela, «Currency Depreciation in Early Modern England and France», Explorations in Economic History, 25 (1988): 75-97.

Hamilton, Earl J.: El tesoro americano y la revolución de los precios en España, I5OI-I650, Barcelona, Crítica, I975.

Hamilton, Earl J., Guerra y precios en España, I65I-I80o, Madrid, Alianza, I980.

Heiss, Aloiss, Descripción general de las monedas hispanocristianas desde la invasión de los árabes. Madrid, I865-I869 (3 tomos).

Hernández, Bernat, «Hombres de negocios y finanzas públicas en la Cataluña de Felipe II», Revista de Historia Económica, I5/I (I997a): 5I-86.

Hernández, Bernat, «Barcelona i Catalunya dins la ruta imperial dels metalls preciosos. Les llicències de propi ús concedides per la Generalitat, I559-I599», en Joan Roca i Albert (coord.), La formació del cinturó industrial de Barcelona, Barcelona, Institut municipal d'História de Barcelona, I997b: 23-35.

Hernández, Bernat, Fiscalismo y finanzas en la Cataluña moderna. La fiscalidad catalana en época de Felipe II, Barcelona, Taller de Estudios Hispánicos e Hispanoamericanos, 2003. 
Jarque Martínez, Encarna \& Salas Ausens, José Antonio, «La Diputación aragonesa en el siglo XVI», Ius Fugit, IO-II (200I-2002): 29I-349.

Lastanosa, Vincencio Juan de, Tratado de la moneda jaquesa y de otras de oro y plata en el reino de Aragón, Zaragoza, s.n., I68I

López GonZÁlez, Clemente, «Desde las reformas de los Reyes Católicos hasta fines del siglo XVII», en Juan Hernández Andreu (coord.), Historia monetaria y financiera de España, Madrid, Síntesis, I996: 13-62.

Martín Corrales, Eloy, «La saca de plata americana desde España hacia el Mediterráneo musulmán, I492-I830», en Antonio-Miguel Bernal Rodríguez (ed.), Dinero, moneda y crédito en la monarquía hispánica, Madrid, Fundación ICO, 2000: 47I-85.

MATEOS Royo, José Antonio, «Sobre tasas y monedas, ferias y usuras: municipio y mercado en Daroca bajo Juan Il y Fernando el Católico (I459-I516)», Aragón en la Edad Media, XIII (I997): I95-215.

MATEOS Royo, José Antonio, «Circulación monetaria, intervención pública y arbitrismo en el reino de Aragón durante el siglo XVIl, Pedralbes, 26 (2006): 153-87.

MAteos Royo, José Antonio, «Política estatal y circulación monetaria: el vellón en Aragón durante el siglo XVIII», Estudis, 35 (2009): I65-96.

Mateos Royo, José Antonio, «Comercio, deuda censal y violencia legal: las instituciones públicas aragonesas ante las marcas de Cataluña (I484-1564)», Studia Histórica. Historia Moderna, 4I/ I, (2019): 29I-322.

MATEU y LlOPIS, Felipe, La ceca de Valencia y las acuñaciones valencianas de los siglos XIII al XVIII, Valencia, viuda de Miguel Sanchís, I929.

MATEU y LlOPIS, Felipe, «Un manuscrito referente a moneda aragonesa conservado en el museo arqueológico nacional», Hispania, X (1943): 580-97.

MATEU Y Llopis, Felipe, La moneda española (breve historia monetaria de España). Barcelona, Alberto Martín, I946.

Mateu y Llopis, Felipe, «El sistema monetario del reino de Aragón. Síntesis histórica», en La moneda aragonesa, Zaragoza, Institución Fernando el Católico, I983: 93-I34.

МотомURA, Akira, «The best and worst of currencies: seigniorage and currency policy in Spain, I597-I650», The Journal of Economic History, 54/I (I994): 104-27.

OrCastegui Gros, Carmen, «La reglamentación del impuesto del monedaje en Aragón en los siglos XIII-XIV», Aragón en la Edad Media, V (I983): II3-2I.

PARKER, Geoffrey, El ejército de Flandes y el camino español, I567-I659, Madrid, Revista de Occidente, 1976.

Pérez García, José Manuel; «Economía y sociedad», en Historia de España, Barcelona, Planeta, I988, vol. VI: I75-334.

Pérez Latre, Miquel, La Generalitat de Catalunya en temps de Felip II. Política, administració i territori, Barcelona, Afers, 2004.

Pérez Sindreu, Francisco de Paula, «Acuñaciones mandadas efectuar en Barcelona, por Carlos I, en I535», Numisma, 230 (1992): 279-295.

Ruiz Martín, Felipe, «Las finanzas españolas durante el reinado de Felipe Il», Hispania, Extra 2 (1968): 109-74.

Ruiz Martín, Felipe, «Joan y Pau Saurí: negociantes catalanes que intervienen en las empresas imperiales de Felipe Il», en Homenaje al Dr. D. Juan Reglà Campistol, Valencia, Universidad, I975, vol. I: 457-78.

Ruiz Martín, Felipe, Pequeño capitalismo, gran capitalismo. Simón Ruiz y sus negocios en Florencia, Barcelona, Crítica, I990. 
Ruiz Trapero, María, «Panorama numismático en la Europa de la Reforma», Cuadernos de investigación histórica, I3 (1990): 27I-82.

Sanahuja Anguera, Xavier, «Reconsideración de la moneda jaquesa de vellón de época moderna (I5I9-I7I7)», Numisma, 247 (2003): 87-I04.

Sanahuja Anguera, Xavier, Fabricació i circulació de moneda local a la Catalunya dels segles XIII-XVI, Lleida, 20I3. Tesis en acceso abierto consultable en http://hdl.handle. net/IO803/II9328

SÁNCHEZ BelÉN, Juan Antonio, «Arbitrismo y reforma monetaria en tiempos de Carlos II», Espacio, Tiempo y Forma, serie IV, 5 (1992): 135-76.

SAntiago Fernández, Javier, Política monetaria en Castilla durante el siglo XVII. Valladolid, Junta de Castilla y León, 2000.

Savall y Dronda, Pascual \& Penén Debesa, Santiago, Fueros, observancias y actos de corte del reino de Aragón, Zaragoza, Castro y Bosque, I866, (2 vols).

Serrano Mangas, Fernando, Vellón y metales preciosos en la Corte del rey de España (I6I8I668), Madrid, Banco de España, I996.

SESMA MUÑoz, José Ángel, «El comercio de exportación de trigo, aceite y lana desde Zaragoza a mediados del siglo XV», Aragón en la Edad Media, I (1977): 20I-38.

SESMA MuÑoz, José Ángel, La Diputación del reino de Aragón en la época de Fernando Il (I4791516), Zaragoza, Institución Fernando el Católico, I982.

SeSMA MuÑoz, José Ángel, «La moneda jaquesa y la emisión de aragoneses de plata», en Homenaje al doctor Antonio Beltrán Martínez, Zaragoza, Universidad, 1986: 1029-39.

Sesma Muñoz, José Ángel, Revolución comercial y cambio social. Aragón y el mundo mediterráneo, Zaragoza, Prensas Universitarias, 2013.

TORRES I SANs, Xavier, Nyerros y cadells: bàndols i bandolerisme a la Catalunya moderna (I590I640), Barcelona, Reial Acadèmia de Bones Lletres, I993.

UlloA, Modesto, La hacienda real de Castilla en el reinado de Felipe II, Madrid, Fundación Universitaria Española, I986.

Vicens Vives, Jaime, Manual de historia económica de España, Barcelona, I959.

VILAR, Pierre, Oro y moneda en la Historia, Barcelona, Ariel, $\mathrm{I} 974$.

VILAR, Pierre, Cataluña en la España moderna, Barcelona, Crítica, 1978 (3 vols).

YUN, Bartolomé, Marte contra Minerva. El precio del Imperio español, c.I450-I60o, Barcelona, Crítica, 2004.

ZulAicA PALACIOS, Fernando, «Economía monetaria y política monetaria en el reino de Aragón en la Edad Media», en XVII Congreso de Historia de la Corona de Aragón, Barcelona, Universidad de Barcelona, 2003, vol. I: 607-32.

ZulAiCA PALACIOS, Fernando, «Una economía en transición: de la crisis a la recuperación», en Ferdinandus, Rex Hispaniarum, príncipe del Renacimiento, Zaragoza, Cortes de Aragón, 2006, pp. 295-307. 


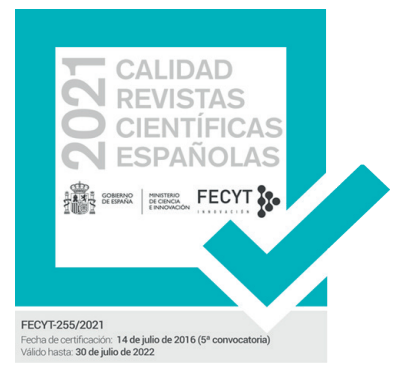

SERIE IV HISTORIA MODERNA

REVISTA DE LA FACULTAD DE GEOGRAFÍA E HISTORIA

AÑO 2021

ISSN: 1131-768X

E-ISSN 2340-1400

\section{4 \\ 西 ESPACIO, TIEMPO Y FORMA}

Monográfico - Special Issue: La política ultramarina de las monarquías ibéricas (circa 1700-1750): una historia de fracasos y éxitos relativos The Overseas Policy of the Iberian Monarchies (Circa 1700-1750): A History of Failures and Relative Successes

15 Roberto Quirós Rosado y MARIA FERnANDA BICALHO La política ultramarina de las monarquías ibéricas (circa 1700-1750): una historia de fracasos y éxitos relativos / The Overseas Policy of the Iberian Monarchies (Circa 1700-1750): A History of Failures and Relative Successes

\section{Guillaume Hanotin}

Defender negocios en tiempo de convulsión política: las elites mercantiles francesas durante la guerra de Sucesión española / Protecting Business in Time of Crisis: French Trademen during the War of Spanish Succession

\subsection{Maria Fernanda Bicalmo}

Ultramarino y el auge de los secretarios de Estado en Portugal durante la primera mitad del siglo XVIII / Sobre este modo de resolver e despachar os negócios. The decline of the Overseas Council and the Rise of the Secretaries of State in Portugal during the First Half of the $18^{\text {th }}$ Century

\section{9}

\section{VALENTINA FAVARò}

El fracaso de los proyectos de reforma en el virreinato peruano de principios

del siglo XVIII. Las propuestas de Carmine Nicola Caracciolo, príncipe de Santobuono the Eighteenth Century. The Proposals of Carmine Nicola Caracciolo, Prince of Santobuono

\section{7}

\section{ROBERTO QUIRÓS ROSADO}

Ecos de un mercantilismo truncado. El conde de Pinos Puente y la diplomacia comercial de Carlos VI en la corte de Lisboa (1723-1724) / Echoes of a Failed Mercantilism. The Count of Pinos Puente and the Commercial Diplomacy of Charles VI at the Court Of Lisbon (1723-1724)

\section{Junia Ferreira Furtado}

Portuguese America under Foreign Threat and the Creation of the Concept of uti possidetis in the First Half of the $18^{\text {th }}$ Century / La américa portuguesa bajo la amenaza exterior y la creación del concepto de uti possidetis en la primera mitad del siglo XVIII

\section{Miscelánea $\cdot$ Miscellany}

\section{José Antonio Mateos Royo}

con Cataluña / Trade Policy and Monetary Circulation in Aragon: Conflicts and Agreements with Catalonia (1535-1565)

\section{Fernando Altoé}

panegíricos atribuidos a la impresion. Un estudio de la trayectoria de dos the Trajectory of Two Panegyrics Attributed to João de Barros

\section{Francisco Velasco Hernández}

reino de Murcia (siglos XVI y XVII) / The Influence of the Berber Corsican on the Late Repopulation on the Coastal Area on the Kingdom of Murcia (XVI and XVII Centuries)

\section{José Antonio Martínez Martínez}

Criados, jornaleros y esclavos al servicio de la familia: la servidumbre de Serfdom of the Muñoz de Otálora in the $17^{\text {th }}$ Century

\section{Víctor Daniel Regalado González-Serna}

Benito de Medina a raíz de su ingreso en el cabildo catedral de Sevilla en 1669 / «Not a Single Good Portuguese». Accusations against Priest Alonso Benito de Medina when Entering the Cathedral Chapter of Seville in 1669

\section{José Herrera Reviriego}

organigrama comercial y militar de la Gober a tólo mitad del siglo XVII / "Only Time will Tell us»: The Role of Taiwan within the Commercial and Military Organization of the Philippine's Governoration during the First Half of the Seventeenth Century

\section{Manuel-Reyes García Hurtado}

de Rande, 1719-1733 / Vicissitudes of the Rescue Companies of the Sunken Ships in the Battle of Rande, 1719-1733

\subsection{Marcos de Miguel Muñoz}

Caballeros in 1769 


\section{4 ESPACIO, TIEMPO Y FORMA}

\section{Javier Tinoco Domínguez}

Tensiones sociopolíticas en el marco del catastro de Ensenada en Jerez de la Frontera: estudio de un conflicto institucional / Socio-Political Tensions within the Framework of Cadastre of Ensenada In Jerez de la Frontera: A Studying of an Institucional Conflict

\section{Pablo Fernández Albaladejo}

Fábulas de origen y gramática de nación en la España del siglo XVIII. A propósito de algunos trabajos de Francisco Martínez Marina / Origin's Fables and Grammar of Nation in the XVIII Century Spain. About some Works by Francisco Martínez Marina

\subsection{José María IÑURRITEgui Rodríguez}

Constitución increada: Francisco Martínez Marina y la crítica bíblica / Uncreated Constitution. Francisco Martínez Marina and Biblical Criticism

\subsection{David A. Abián Cubillo}

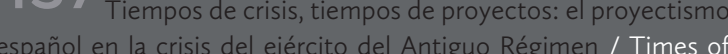
crisis, Times of Projects: The Spanish proyectismo during the Army's Crisis in the Ancient Regime

Taller de historiografía · Historiography Workshop

\section{Ensayos · Essays}

\subsection{ChrISTOPH ROSENMÜLLER}

«Tan peligrosas y feas conspiraciones»: la relación escrita por el embajador austriaco Christoph Migazzi en 1754 sobre la caída del marqués de la Ensenada / «Dangerous and Ugly Conspiracies». The Report of the Austrian Ambassador Christoph Migazzi on the Fall of the Marquis of la Ensenada in 1754

\subsection{Serge Gruzinskı}

Quelle histoire enseigner en 2021 ? / ¿Qué historia enseñar en 2021?

\subsection{Carlos Amate Pizarro}

Las relaciones hispano-chinas en el siglo XVI: síntesis e interpretación a la luz de la reciente historiografía / The Hispanic-chinese Relationship in the XVI Century: Synthesis and Interpretation in the Light of Recent Historiography

\section{Reseñas • Book Review}

521 Bolufer Peruga, Mónica, Arte y artificio de la vida en común. Los modelos de comportamiento y sus tensiones en el Siglo de las Luces, (Julio ArRoyo Vozmediano) 


\section{4 ESPACIO, TIEMPO Y FORMA}

525 Melón, Amando, Alejandro de Humboldt. Vida y obra (Carlos Martínez Shaw)

52 Commentary to Tatiana Seijas' review of The Atlantic World and the Manila Galleons: Circulation, Market, and Consumption of Asian Goods in the Spanish Empire (JosÉ LuIs GASCH TOMAS)

533 Braguier, Laurey, Servantes de dieu. Les beatas de la Couronne de Castille (1450-1600) (Manuela Águeda GARCÍA-GARRIDO)

539 Romeo, María CRuz; SAlomón, María Pilar; TABANERA, Nuria (eds.): Católicos, Reaccionarios y Nacionalistas. Política e identidad nacional en Europa y América Latina Contemporáneas (JAVIER M. Dos SANTOS)

54 Heredia López, Alfonso Jesús, El control de la corrupción en la Monarquía Hispánica. La Casa de la Contratación (1642-1660) (José Manuel Díaz Blanco)

17 Andújar Castillo, Francisco, El Atila de Madrid. La forja de un banquero en la crisis de la monarquía (1685-1715) (Aitor Díaz PAREdes)

551 Serrano Aviles, Javier y Mojarro, Jorge (eds.) Prada GonzALEZ, María (coord. de ilustraciones), En el archipiélago de la Especiería. España y Molucas en los siglos XVI y XVII (İ̃̃ıGo VALPUESTA VILLA)

555 Díaz Ceballos, Jorge, Poder compartido. Repúblicas urbanas, Monarquía y conversación en Castilla del Oro, 1508-1573 (JUAN SEbAstián Gómez GonZÁleZ)

51 Edelmayer, Friedrich, Massimiliano II, Filippo II I'Italia imperiale. II marchesato di Finale, i diritti imperiali e il «camino spagnolo» (RAFAEL VALLADARES)

56 Escribano-PÁEZ, José M., Juan Rena and the Frontiers of Spanish Empire, 1500-1540 (DAvid Martín Marcos)

56 ARnOLD, David, La Era de los Descubrimientos (1400-1600), Madrid, Alianza Editorial, 2021, 184 Pp., ISBN: 978-841362-172-2 (CARlos Amate Pizarro) 